\title{
Precision Nanotube Mimics via Self-Assembly of Programmed Carbon Nanohoops
}

Jeff M. Van Raden, $+\| *$ Erik J. Leonhardt, $+\| *$ Lev N. Zakharov, ${ }^{\ddagger}$ A. Pérez-Guardiola ${ }^{\S}$, A. J. Pérez-Jiménez ${ }^{\S}, C^{*}$ Checkers R. Marshall, † Carl K. Brozek, † J. C. Sancho-García ${ }^{\S}$, and Ramesh Jasti.*+ll

${ }^{\dagger}$ Department of Chemistry \& Biochemistry and Materials Science Institute, University of Oregon, Eugene, Oregon 97403, United States

"Knight Campus for Accelerating Scientific Impact, University of Oregon, Eugene, Oregon 97403, United States

${ }^{\ddagger}$ CAMCOR - Center for Advanced Materials Characterization in Oregon, University of Oregon, Eugene, Oregon, 97403, United States

${ }^{\S}$ Department of Physical Chemistry, University of Alicante, E-03080 Alicante, Spain

\section{Table of Contents}

Synthetic Schemes........................................................................................................................ S2

NMR Spectra

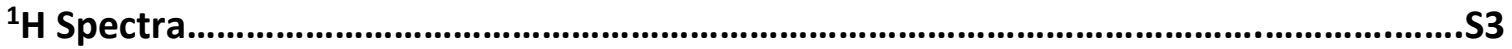

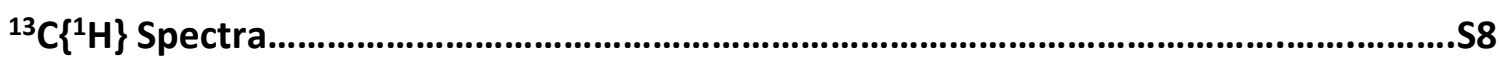

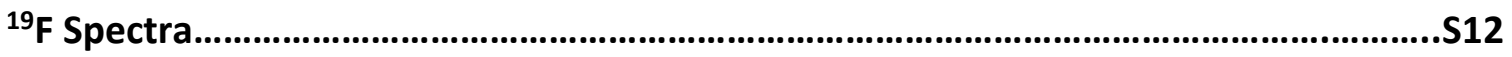

Photophysical data............................................................................................................................S17

Binding Constant $\left(K_{a}\right)$ Determination.......................................................................................S18

Additional Crystallographic data..................................................................................................519

Thermogravimetric (TGA) Analysis of Nanohoop 1...................................................................S26

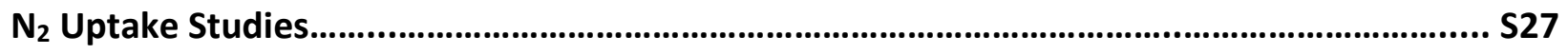

Powder X-Ray Diffraction Data for Nanohoop 1............................................................................S28

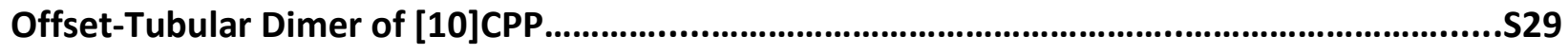

Computational Analysis of Nanohoop 1....................................................................................530

\section{Corresponding Authors:}

Email: rjasti@uoregon.edu

Email: jc.sancho@ua.es 


\section{Synthetic Schemes}

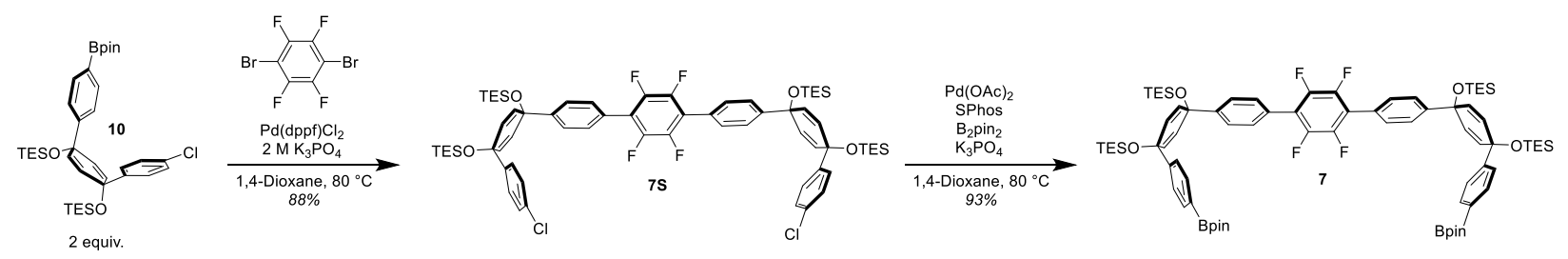

Scheme S1. Synthetic route towards intermediate 7.
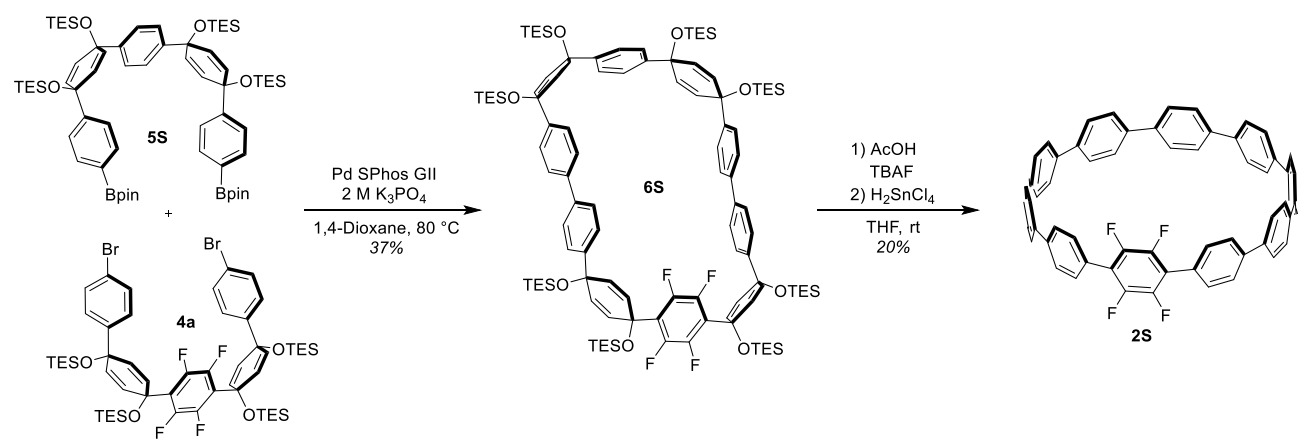

Scheme S2. Synthetic route towards nanohoop $\mathbf{2 S}$. 


\section{${ }^{1}$ H NMR Spectra}
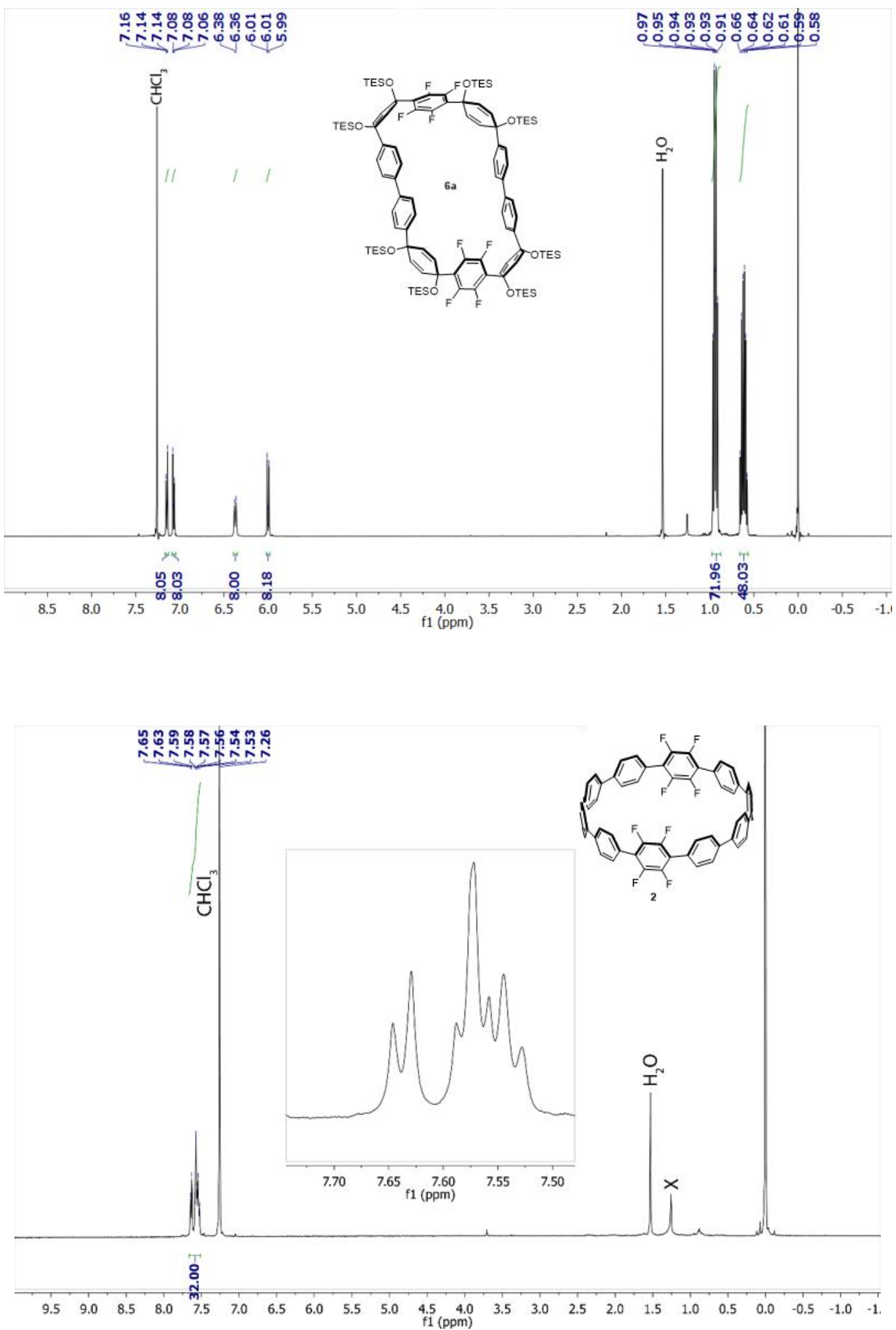


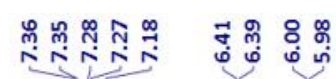

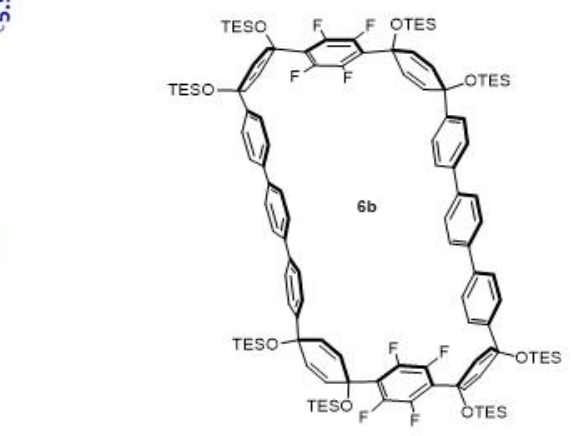

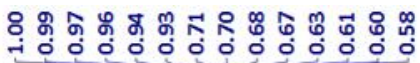

IIS
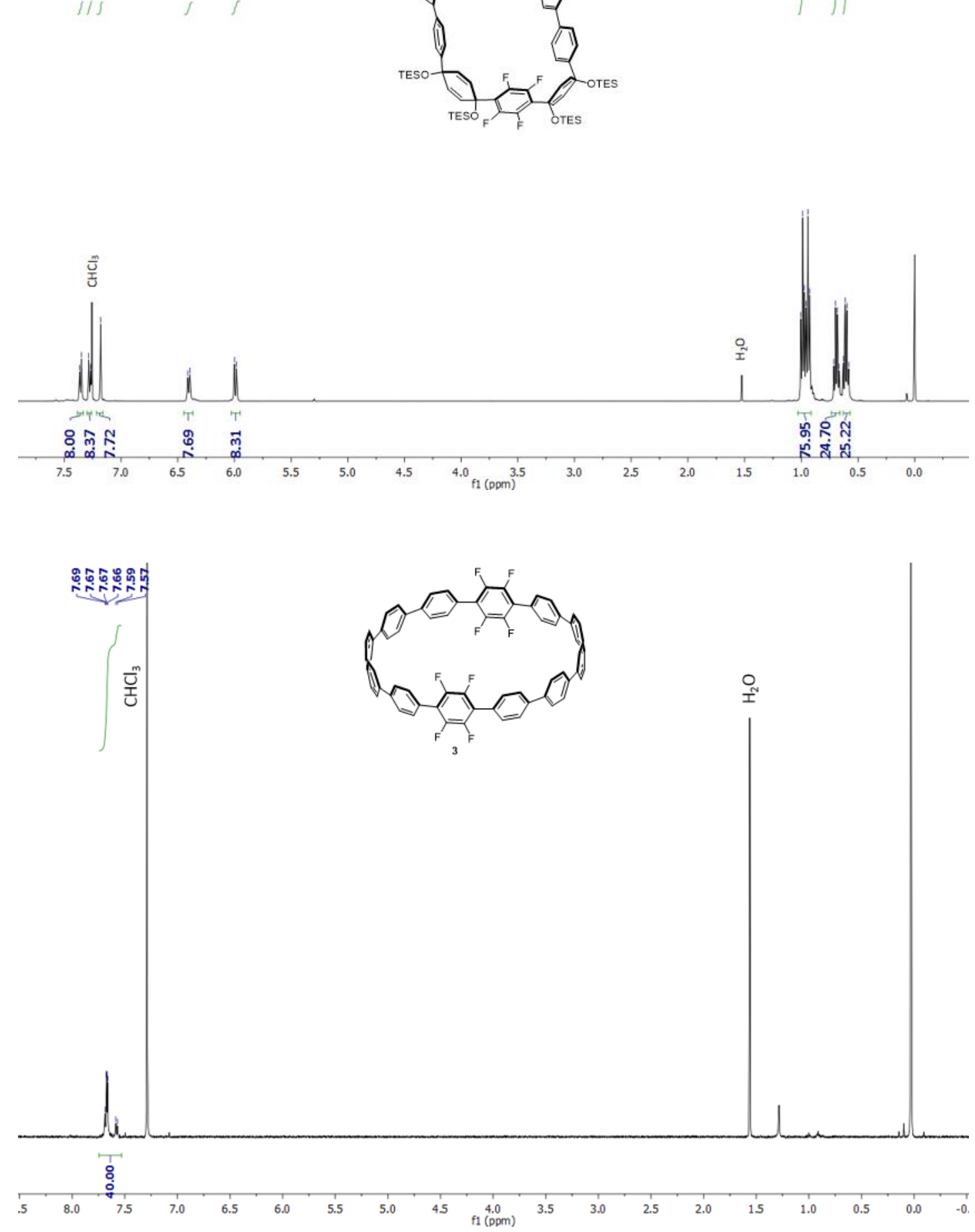

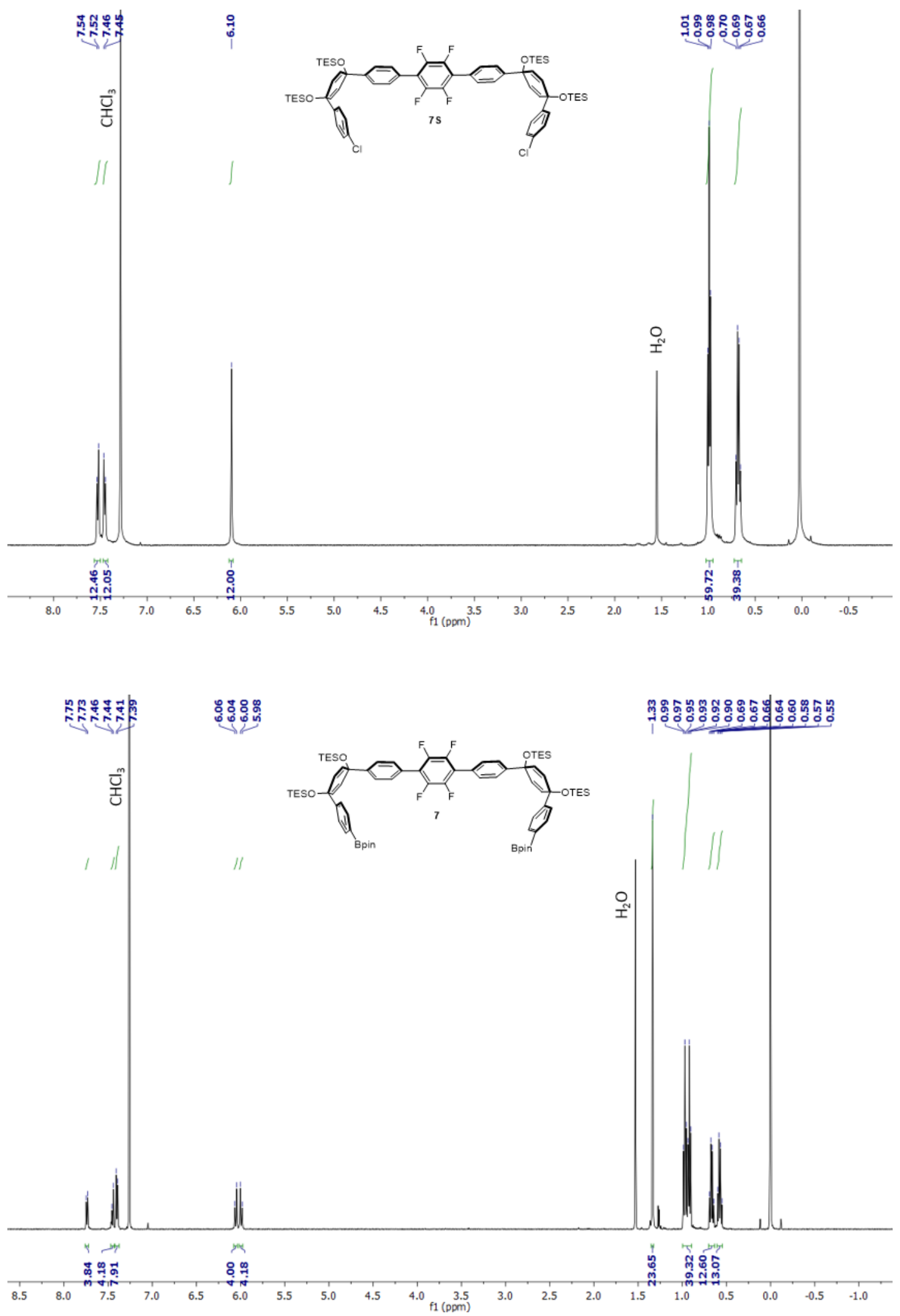

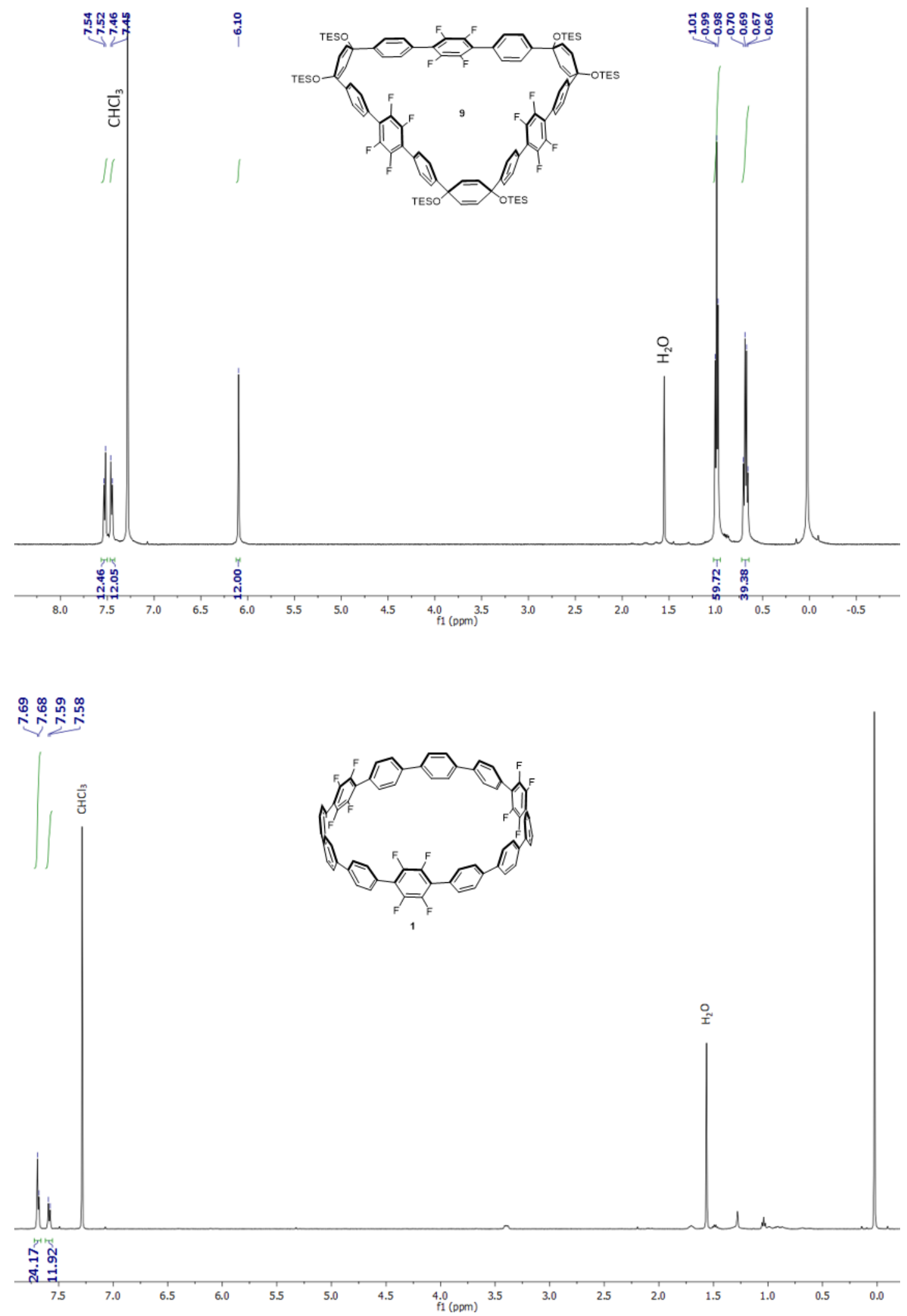


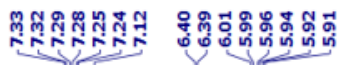

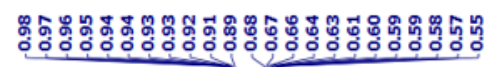
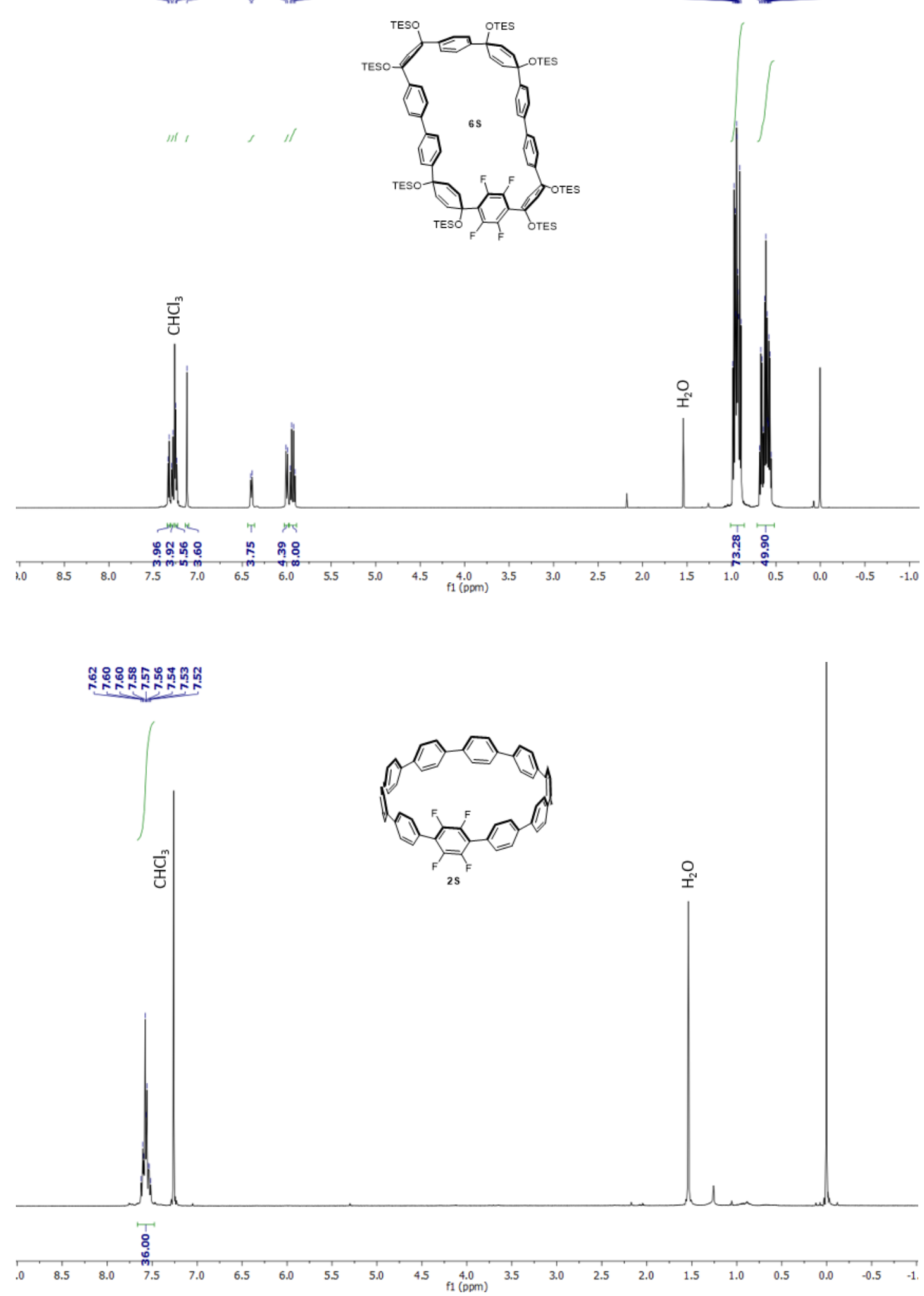
${ }^{13} C\left\{{ }^{1} \mathrm{H}\right\}$ NMR Spectra

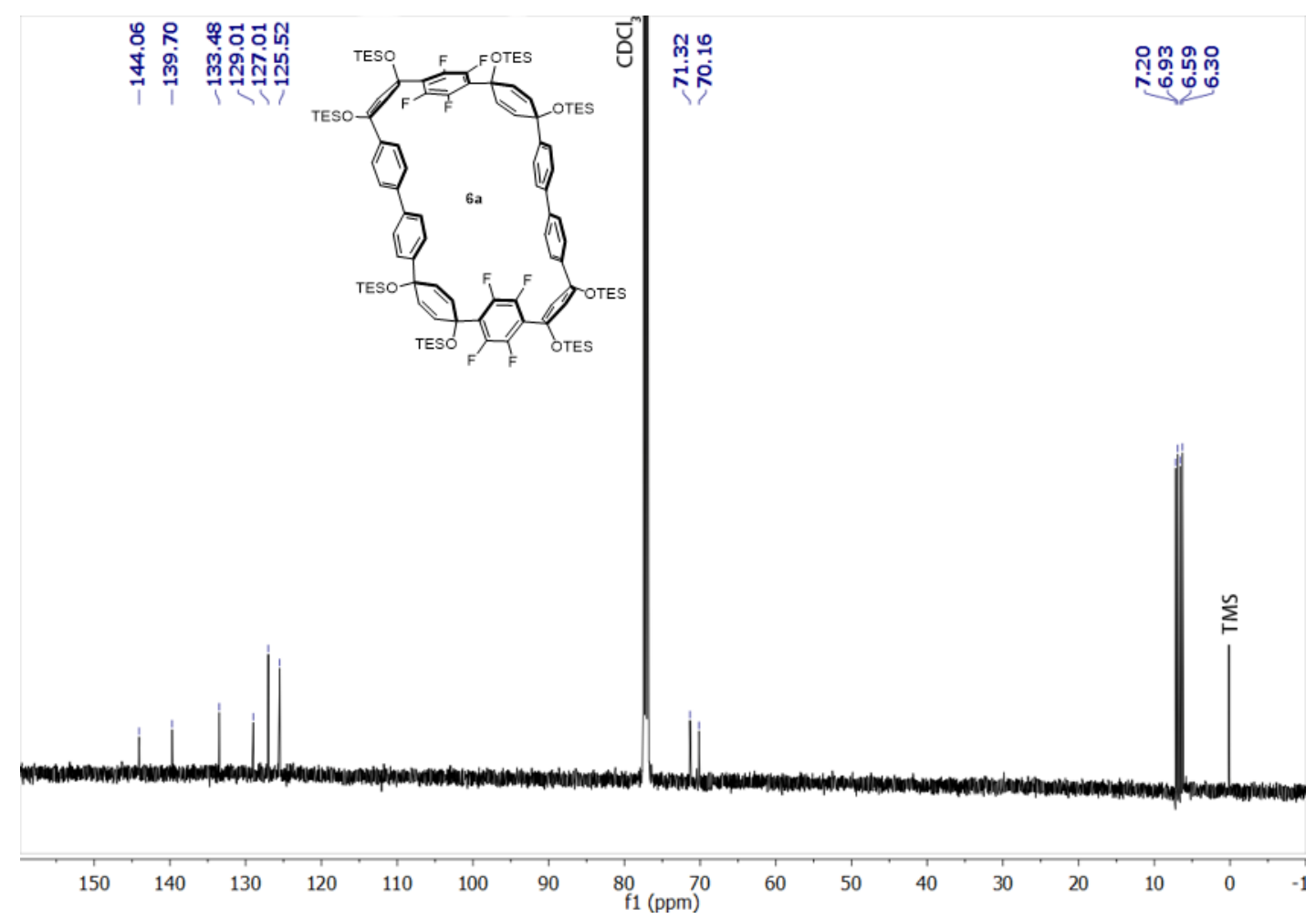

궁유용요 웅

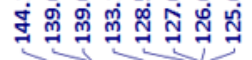

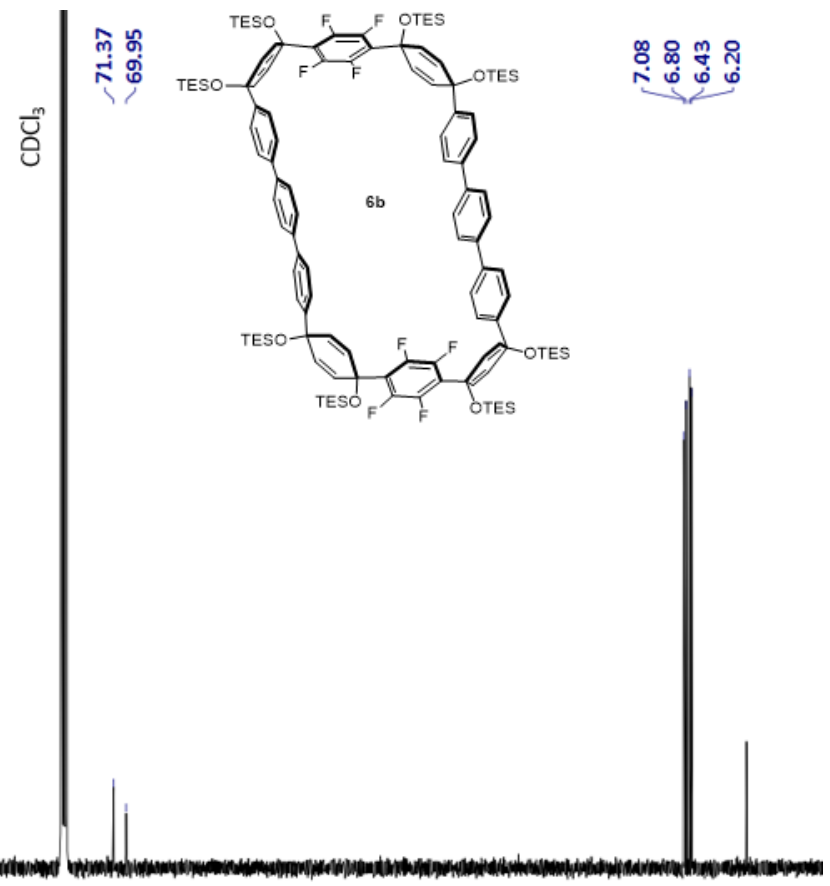

$150 \quad 140 \quad 130$ 120 10 100 $90 \quad 80$

70
$(\mathrm{ppm})$ 

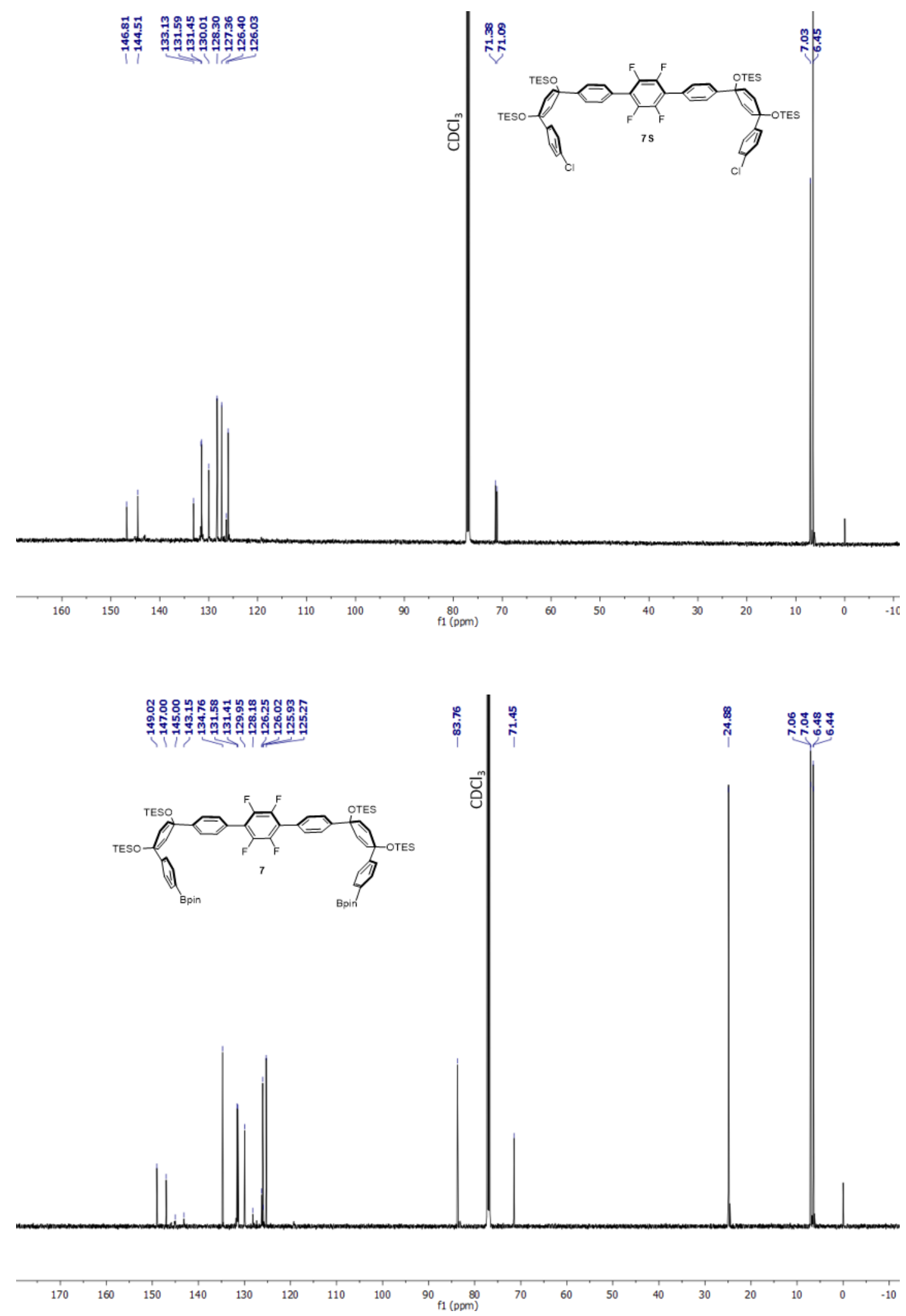

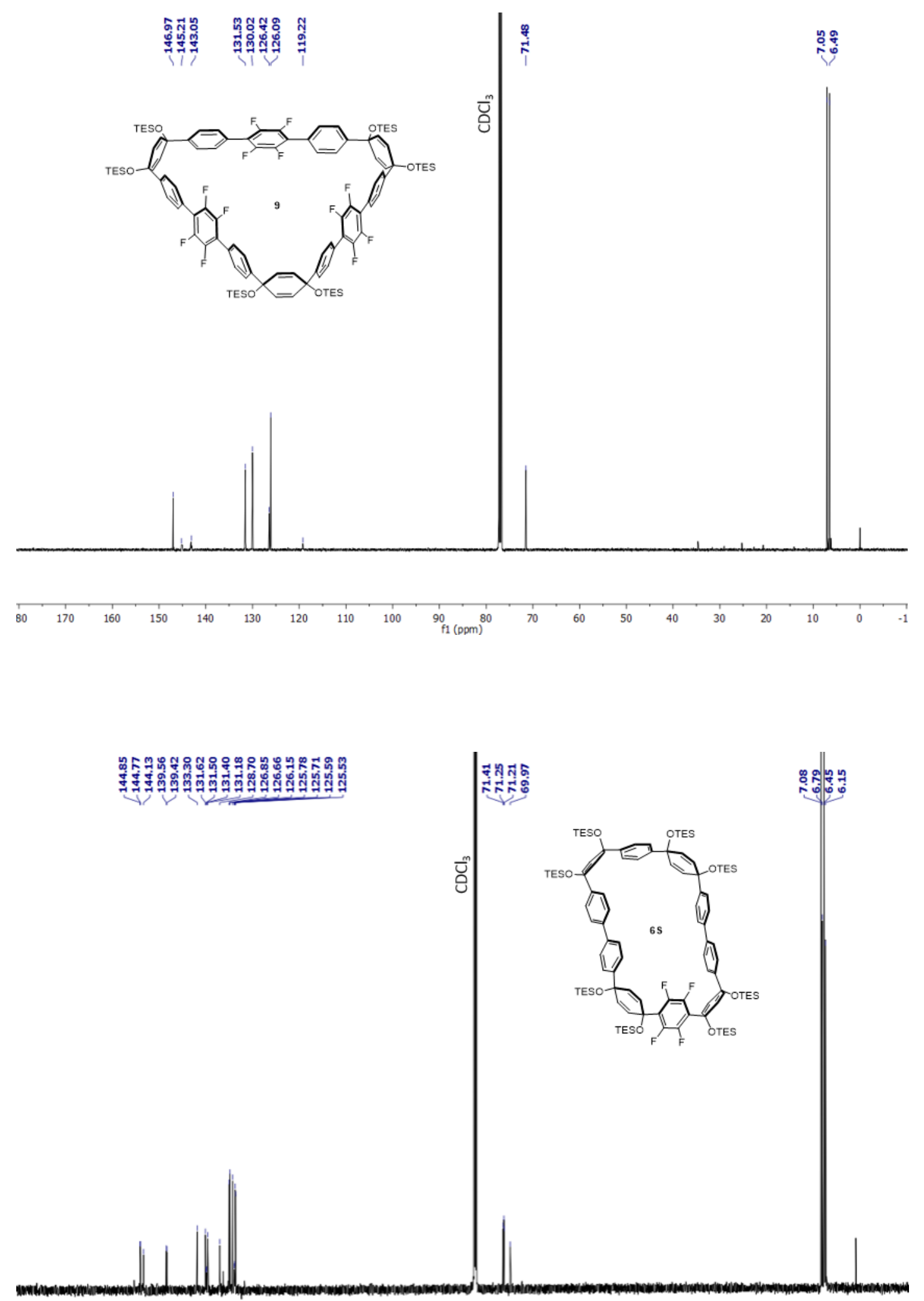


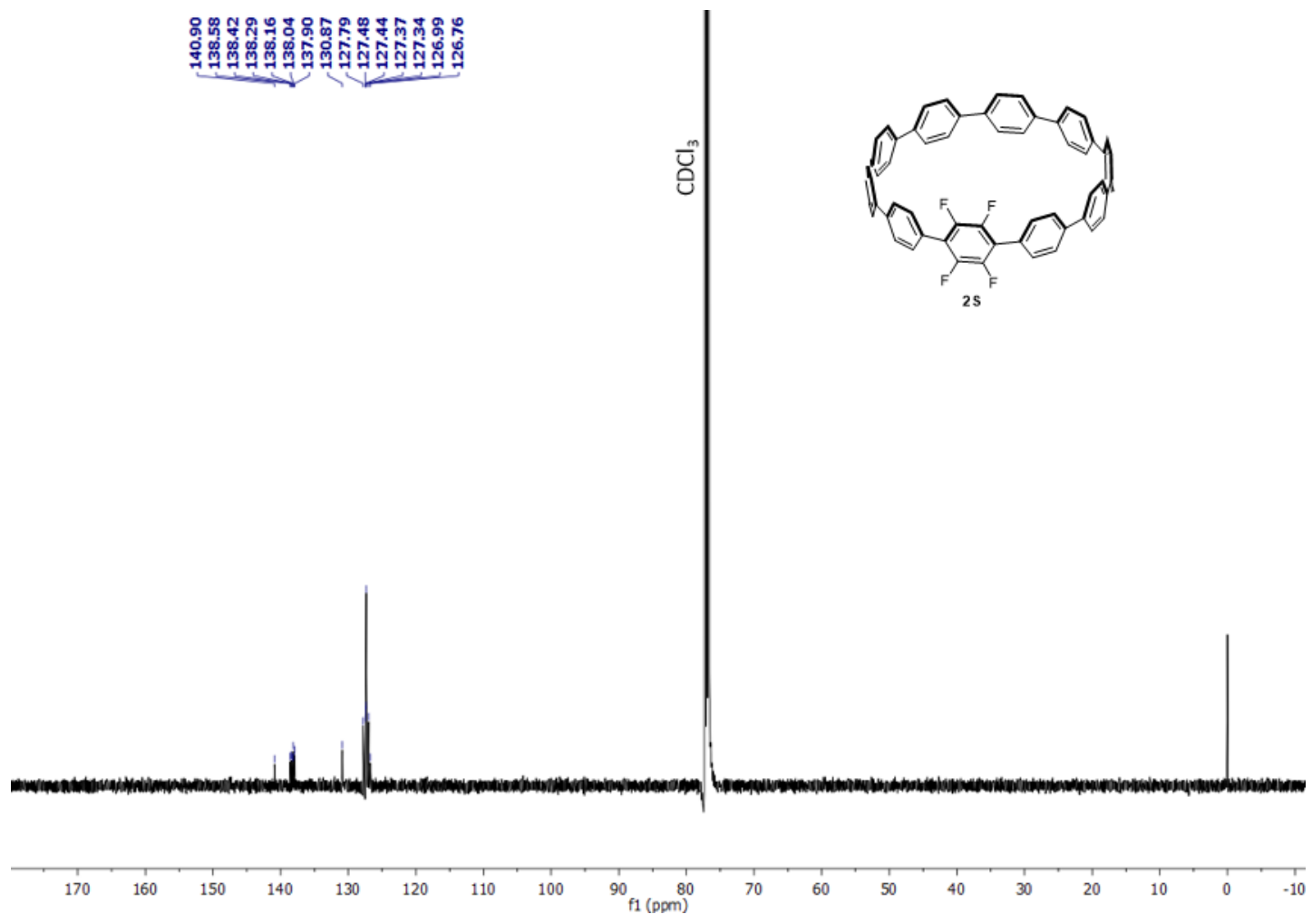


${ }^{19}$ F NMR Spectra

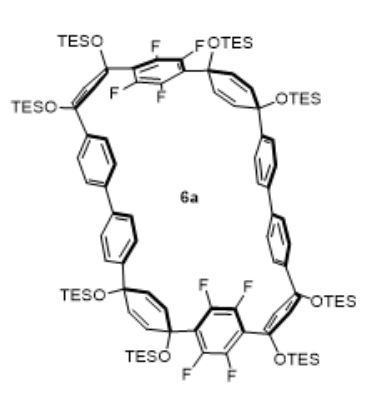

\begin{tabular}{lllllllllllllllllllllllllllll}
\hline 0 & 10 & 0 & -10 & -20 & -30 & -40 & -50 & -60 & -70 & -80 & -90 & -100 & -110 & -120 & -130 & -140 & -150 & -160 & -170 & -180 & -190 & -200 & -210 & -22
\end{tabular}

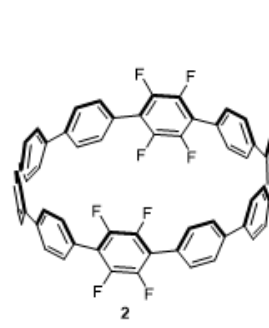

ฟิ

\begin{tabular}{llllllllllllllllllllllllllllll}
\hline 0 & 10 & 0 & -10 & -20 & -30 & -40 & -50 & -60 & -70 & -80 & -90 & -100 & -110 & -120 & -130 & -140 & -150 & -160 & -170 & -180 & -190 & -200 & -210 & -22
\end{tabular} 


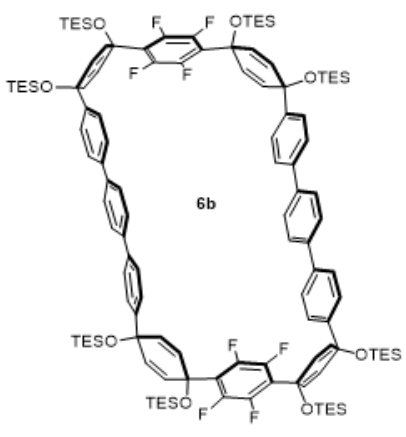

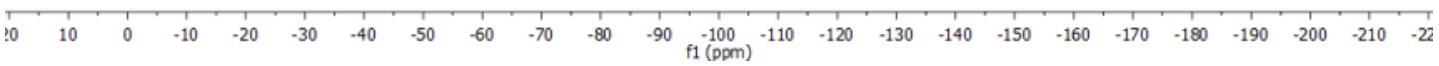

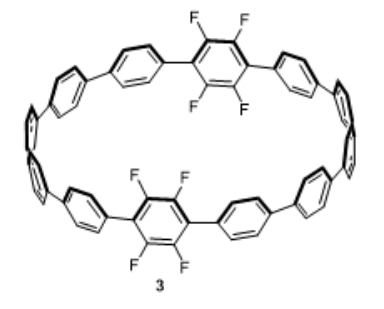

迎

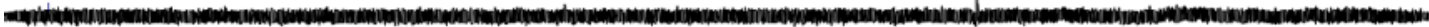

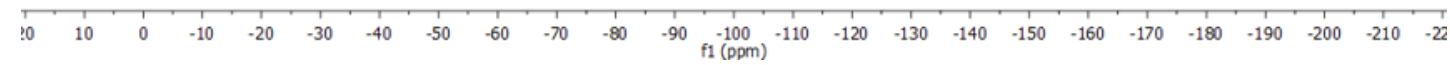




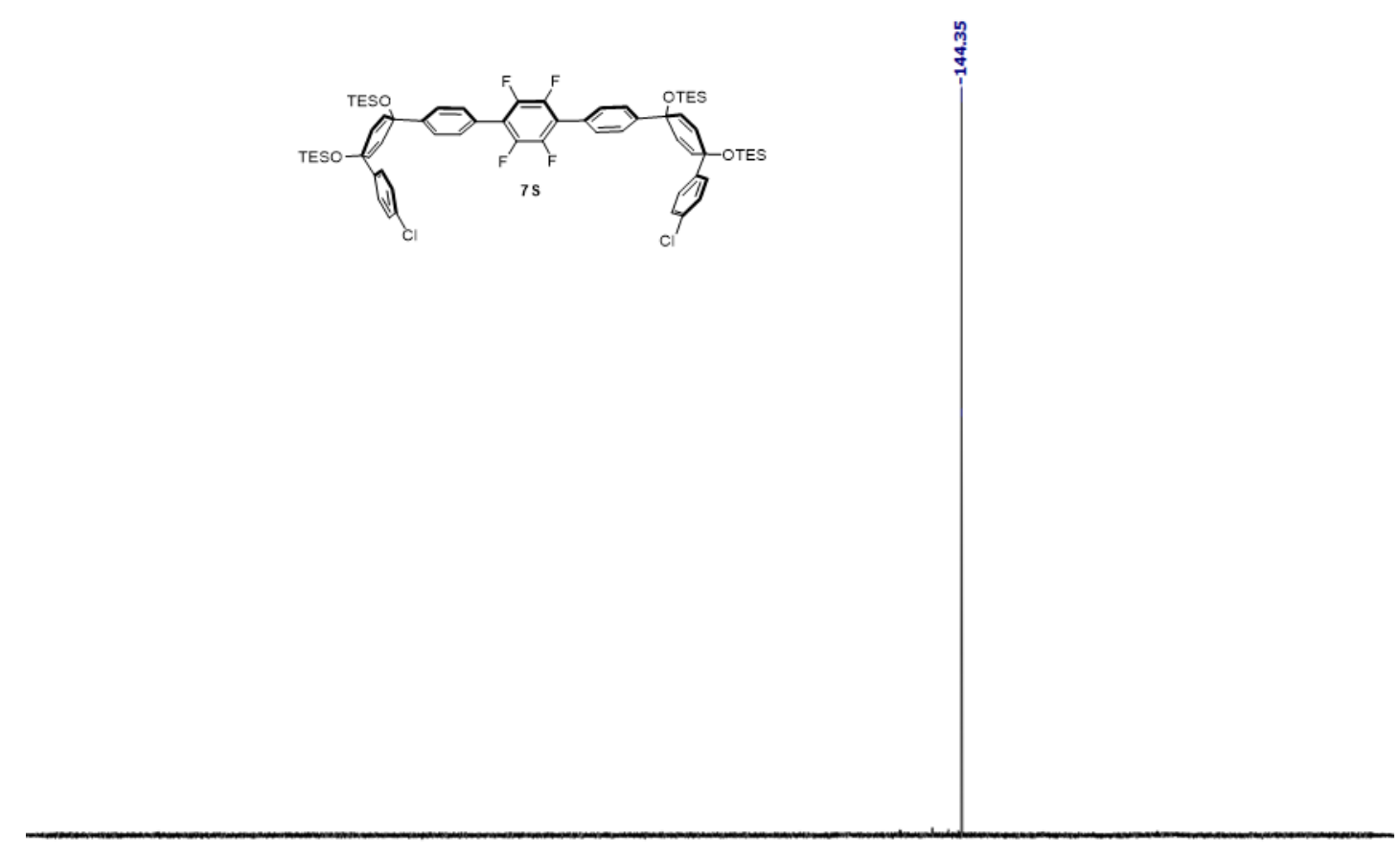

\begin{tabular}{lllllllllllllllllllllllllllllllllllllll}
\hline 0 & 10 & 0 & -10 & -20 & -30 & -40 & -50 & -60 & -70 & -80 & -90 & -100 & -110 & -120 & -130 & -140 & -150 & -160 & -170 & -180 & -190 & -200 & -210 & -22
\end{tabular}

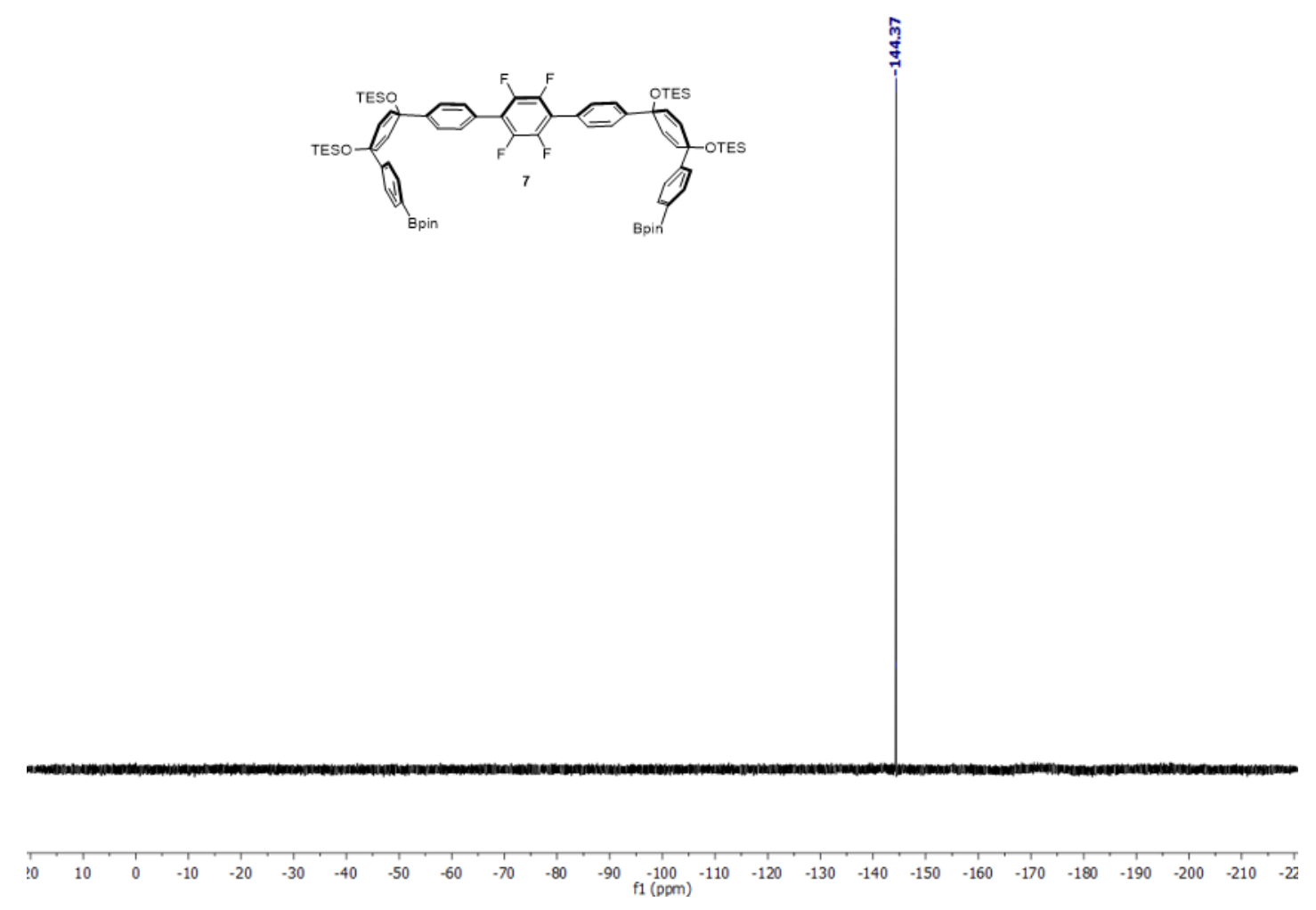



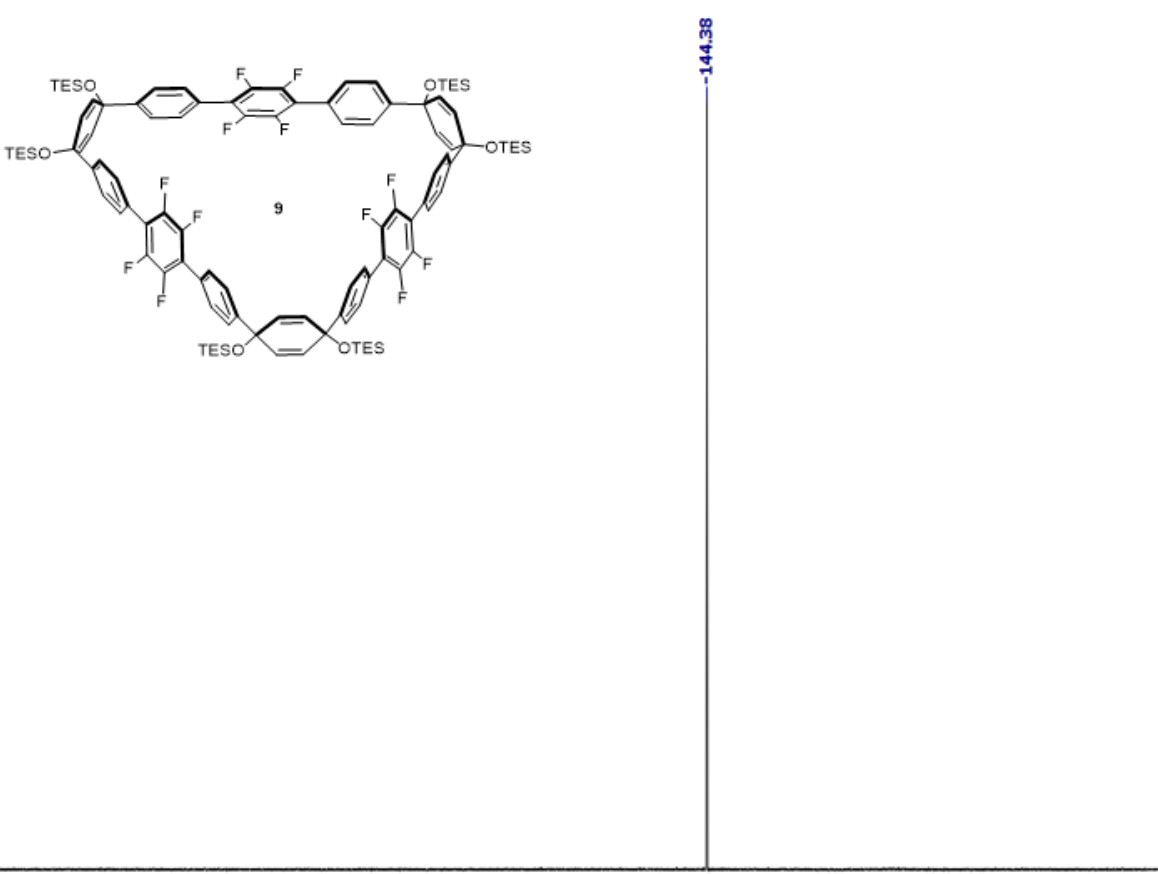

$\begin{array}{llllllllllllllllllllllllllllllllllll}10 & 10 & 0 & -10 & -20 & -30 & -40 & -50 & -60 & -70 & -80 & -90 & -100 & -110 & -120 & -130 & -140 & -150 & -160 & -170 & -180 & -190 & -200 & -210 & -22\end{array}$

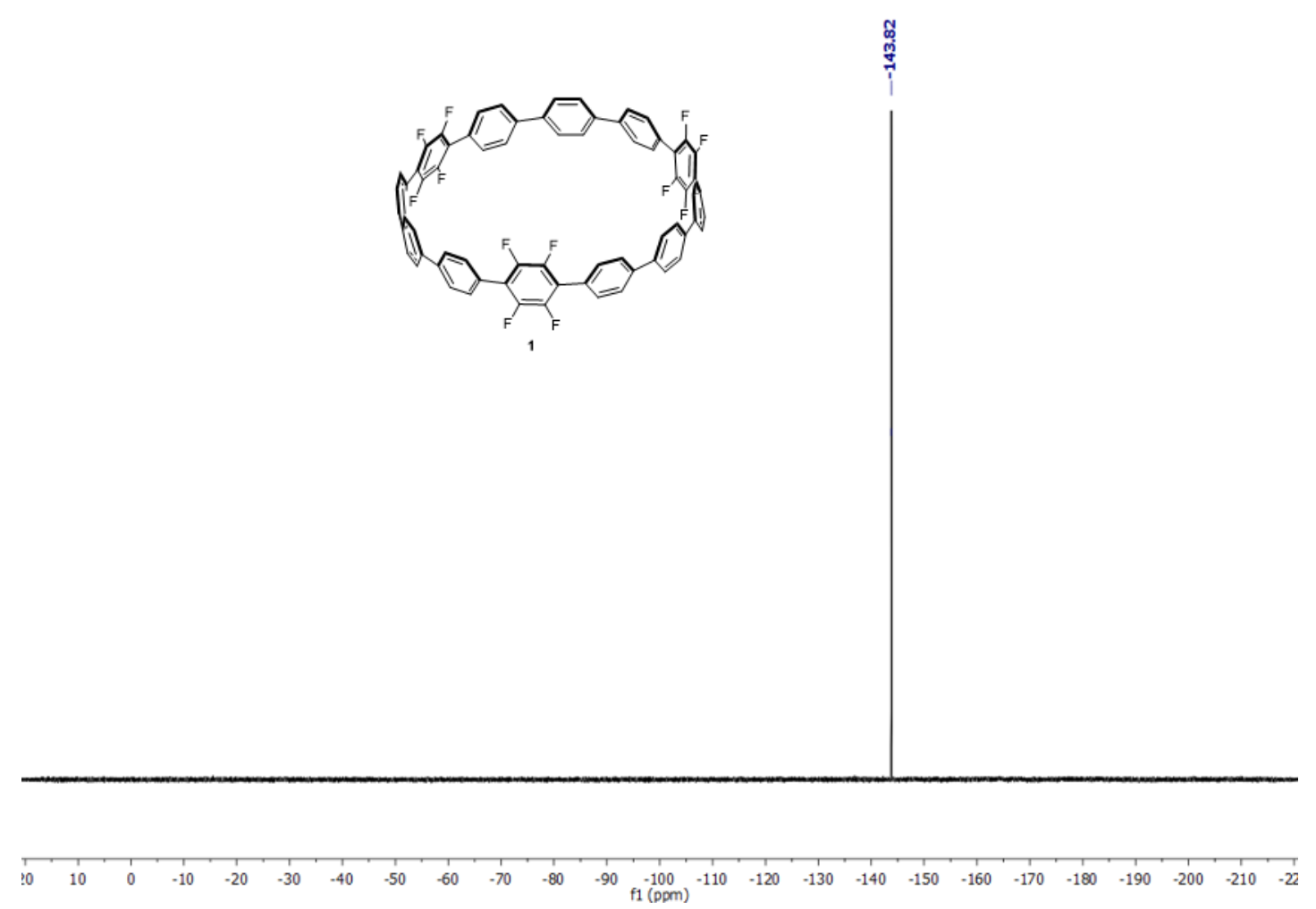


i़
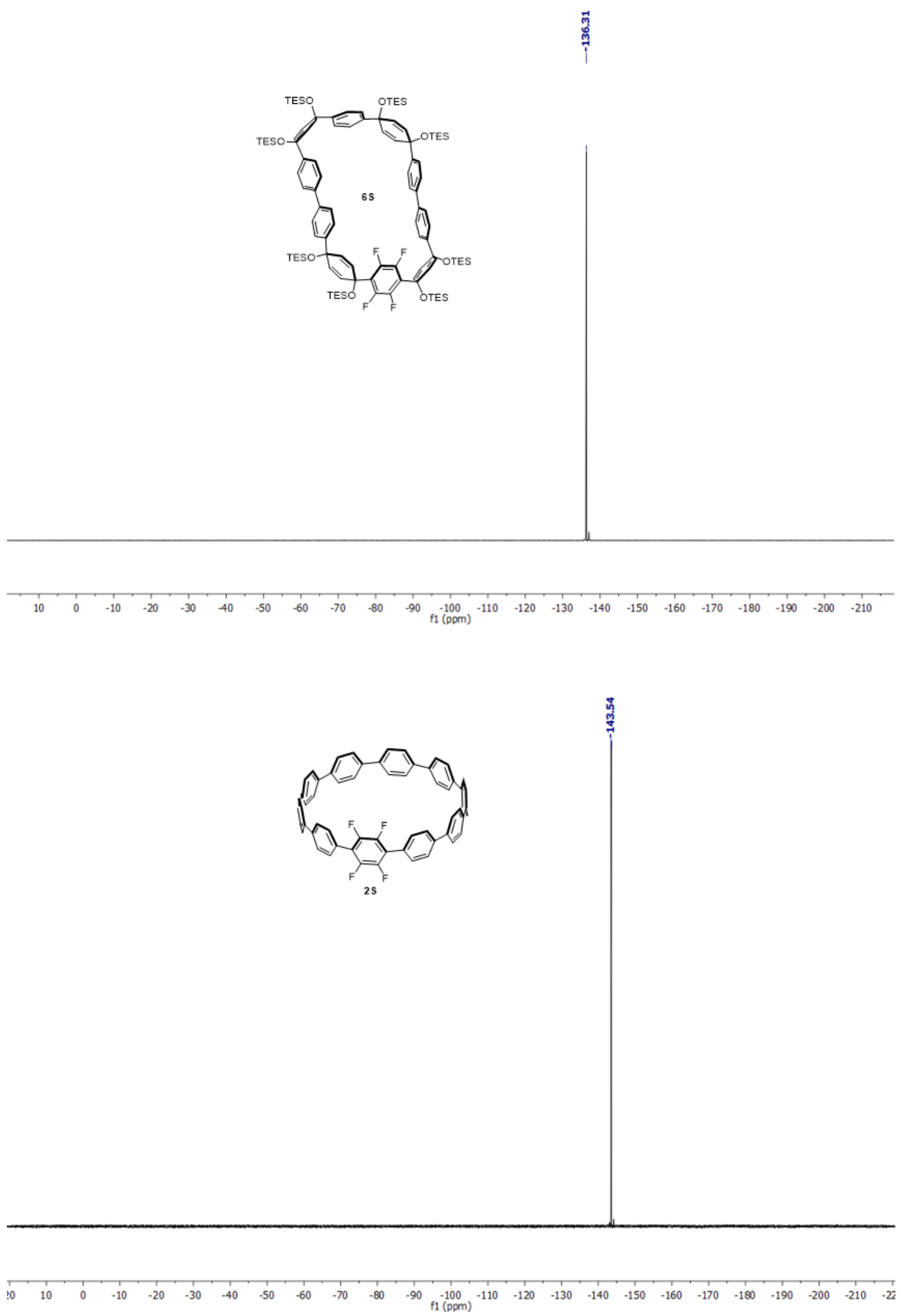

S16 


\section{Photophysical data}

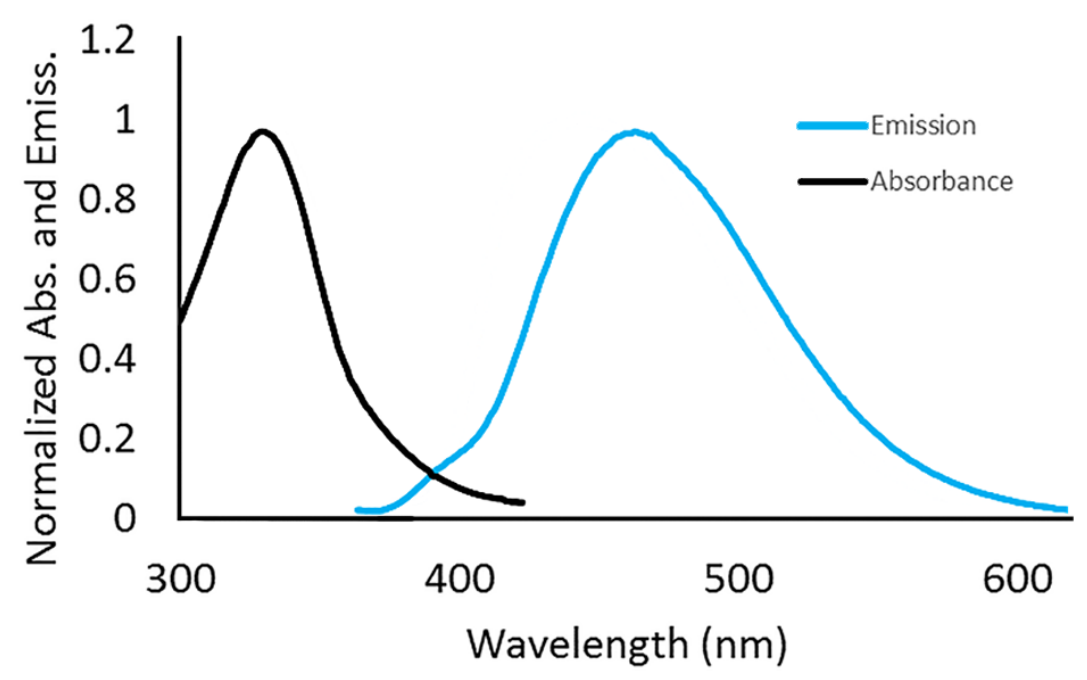

Figure S1. Absorbance and Emission Spectra of Nanohoop 2

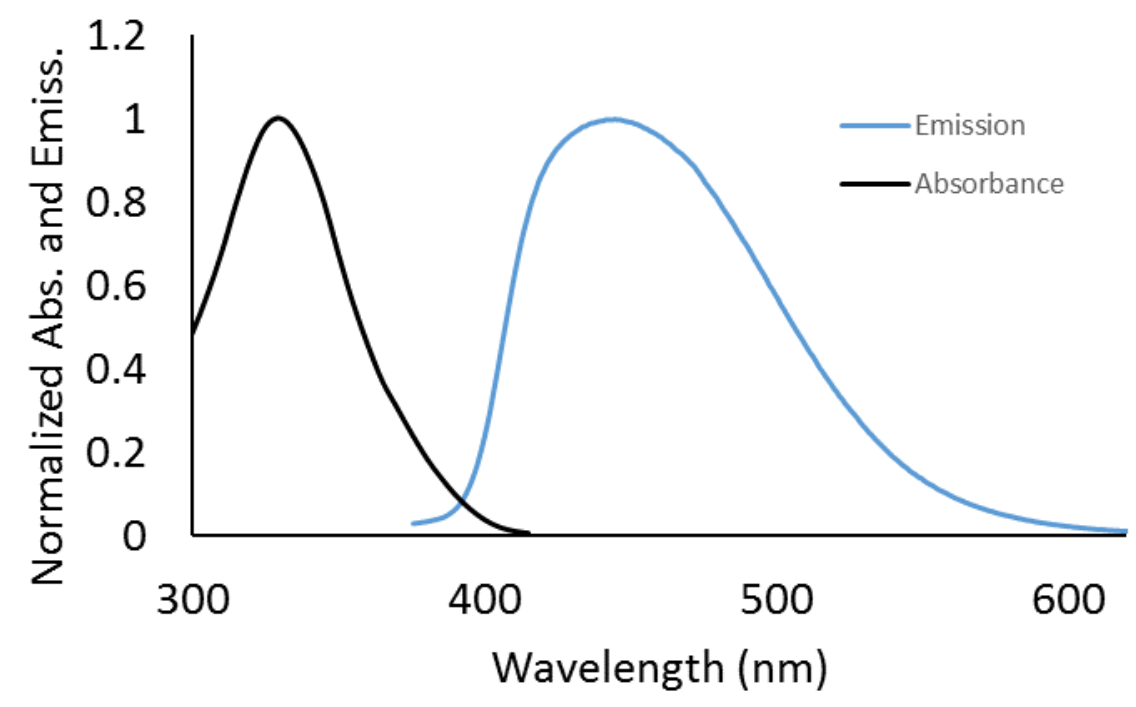

Figure S2. Absorbance and Emission Spectra of Nanohoop 3 


\section{Binding Constant $\left(K_{a}\right)$ Determination}

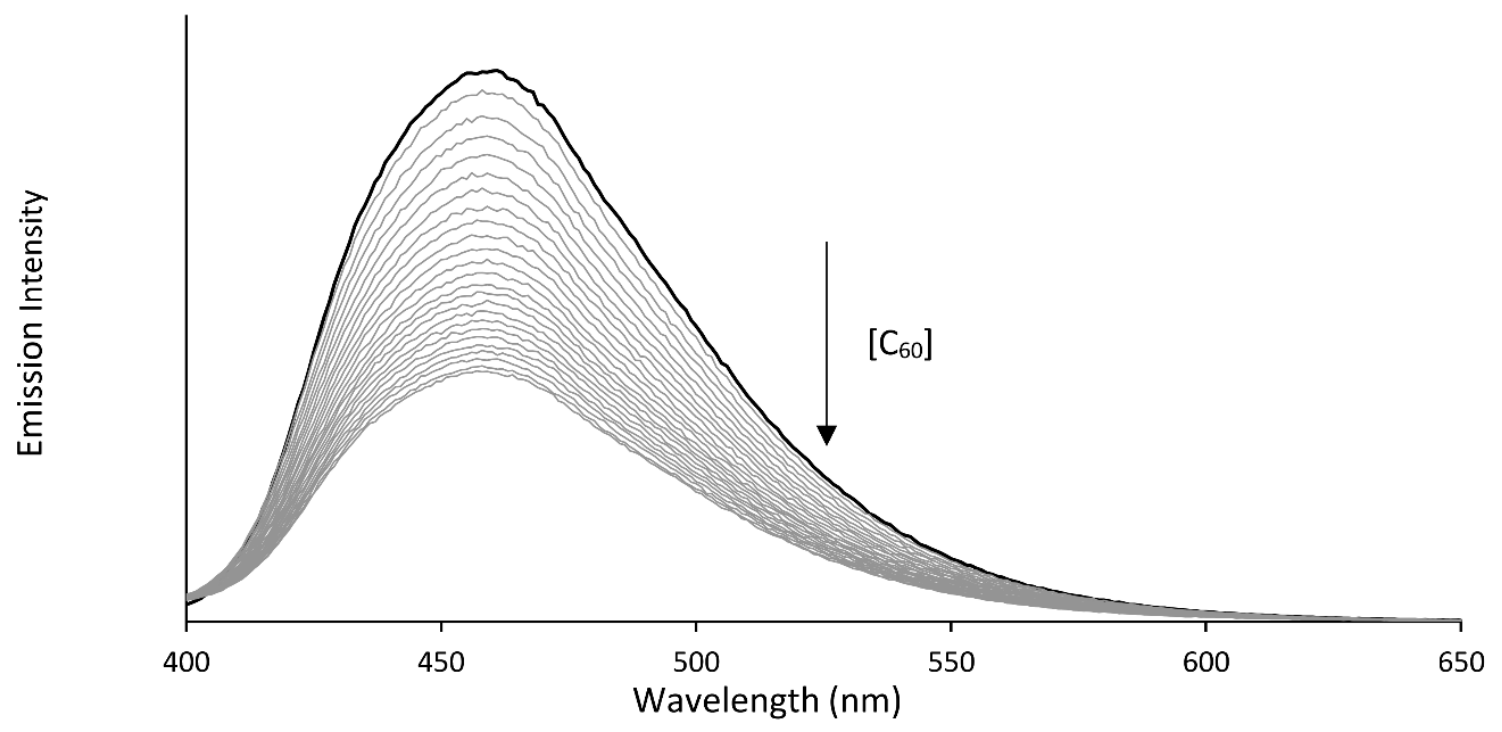

Figure S3. Change in emission intensity fluorinated nanohoop 1 with increasing concentration of C60. The initial concentration of 1 was $5.00 \times 10^{-7} \mathrm{~mol} \mathrm{~L}^{-1}$, while the concentration of $\mathrm{C} 60$ was varied from $0.00-2.88 \times 10^{-7} \mathrm{~mol} \mathrm{~L}^{-1}$.

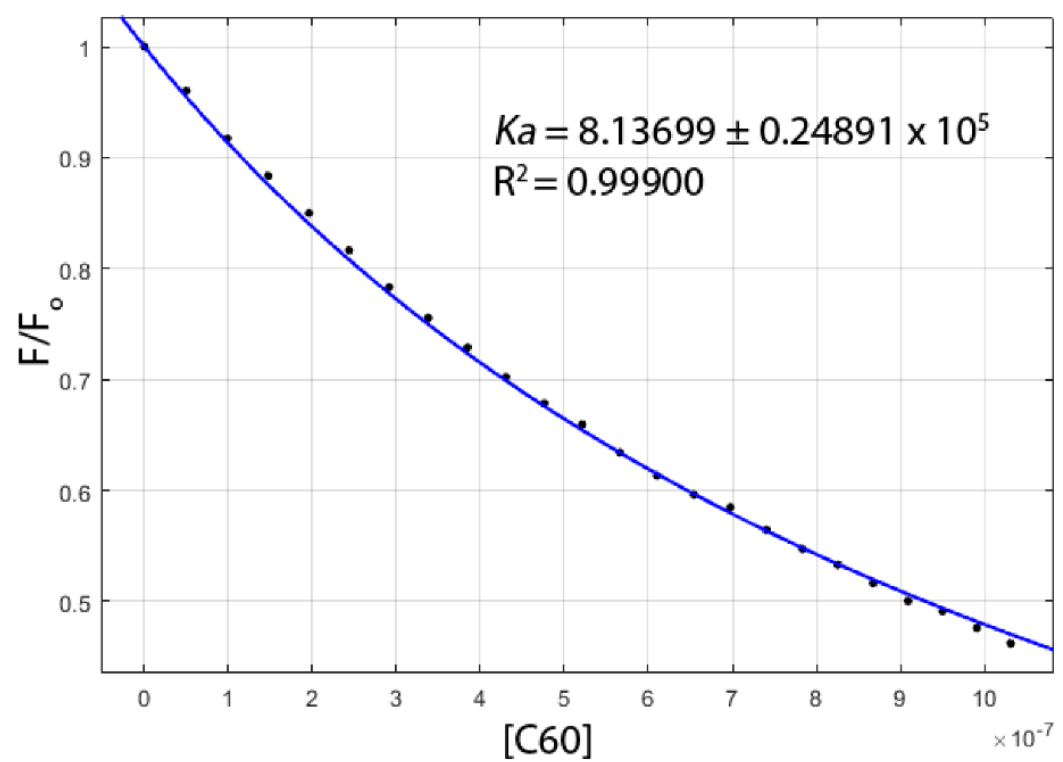

Figure S4. Correlation of $\left[\mathrm{C}_{60}\right]$ on the fluorescence intensity of fluorinated nanohoop $\mathbf{1}$ in toluene. The change in fluorescence at $460 \mathrm{~nm}$ (obtained from Figure S4) was fit to equation 1 to obtain the $K a$. 


\section{Additional Crystallographic Data}

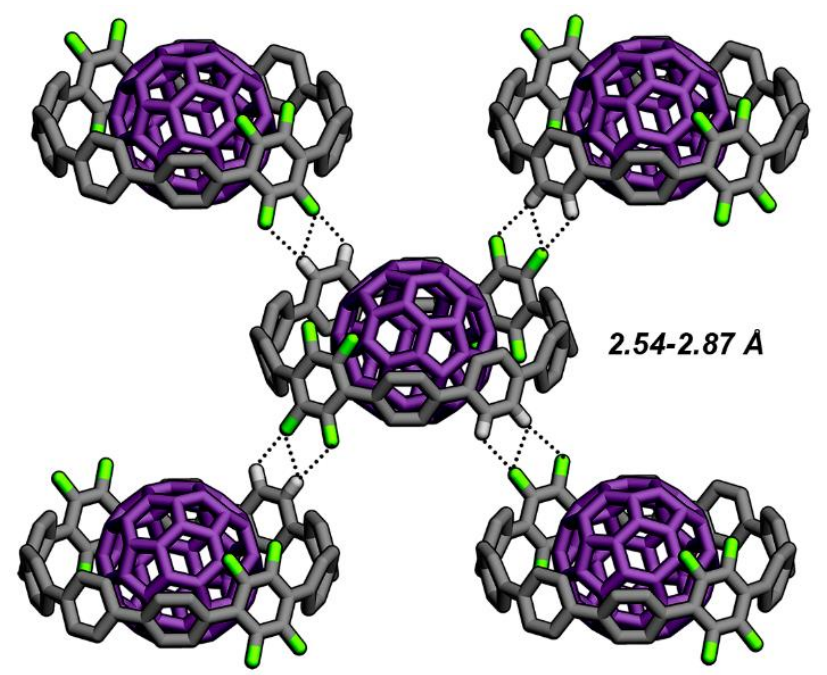

Figure S5. C-H---F interactions (dotted lines) observed in the crystal packing of $\mathbf{2} @ \mathrm{C}_{60}$. C---F distances measure from 3.20-3.81 ̊. 
a)

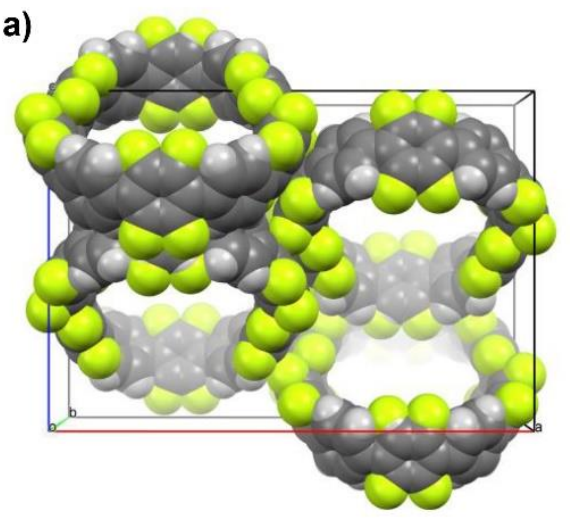

b)

d)

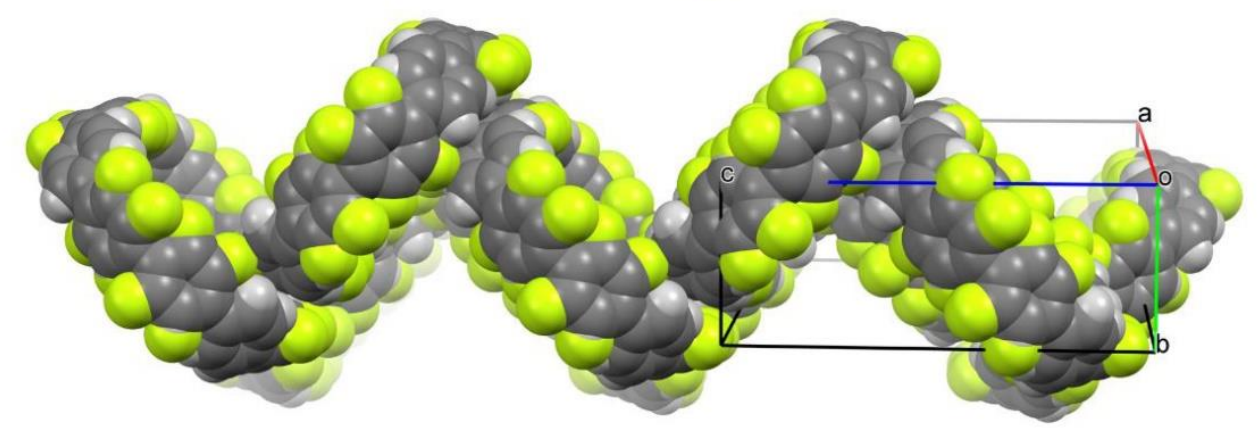

Figure S6. (a-d) Observed solid-state packing of fluorinated nanohoop $2 \mathrm{~S}$, with fluorine atoms disordered across six phenylene moieties. c)

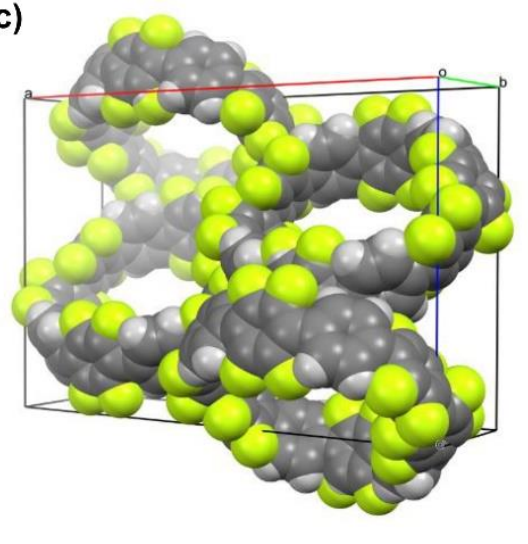




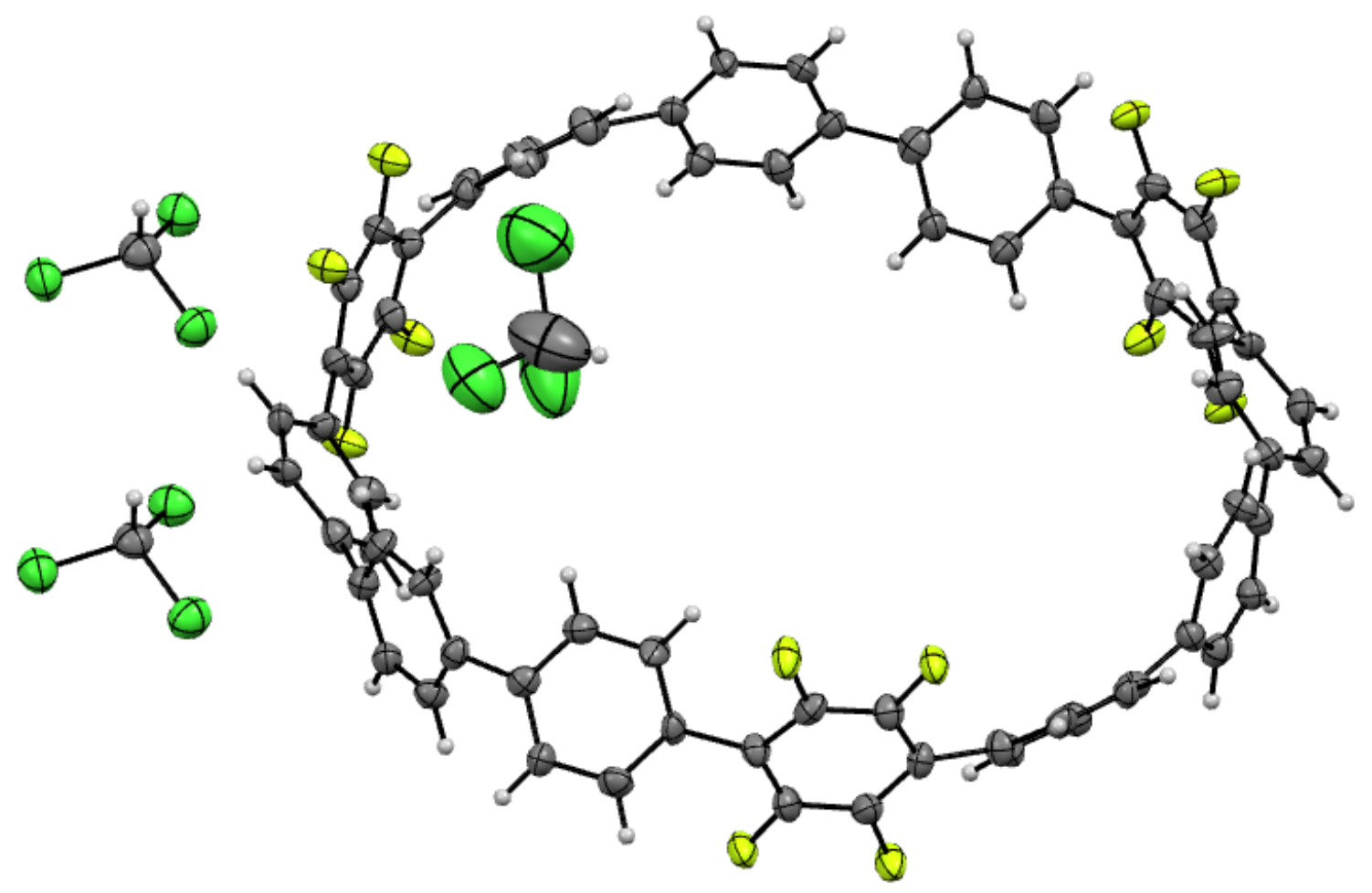

Figure S7. Molecular structure of nanohoop 1, with ellipsoids drawn at the 50\% probability level. Crystals were grown via slow evaporation from $\mathrm{CHCl}_{3}$. 


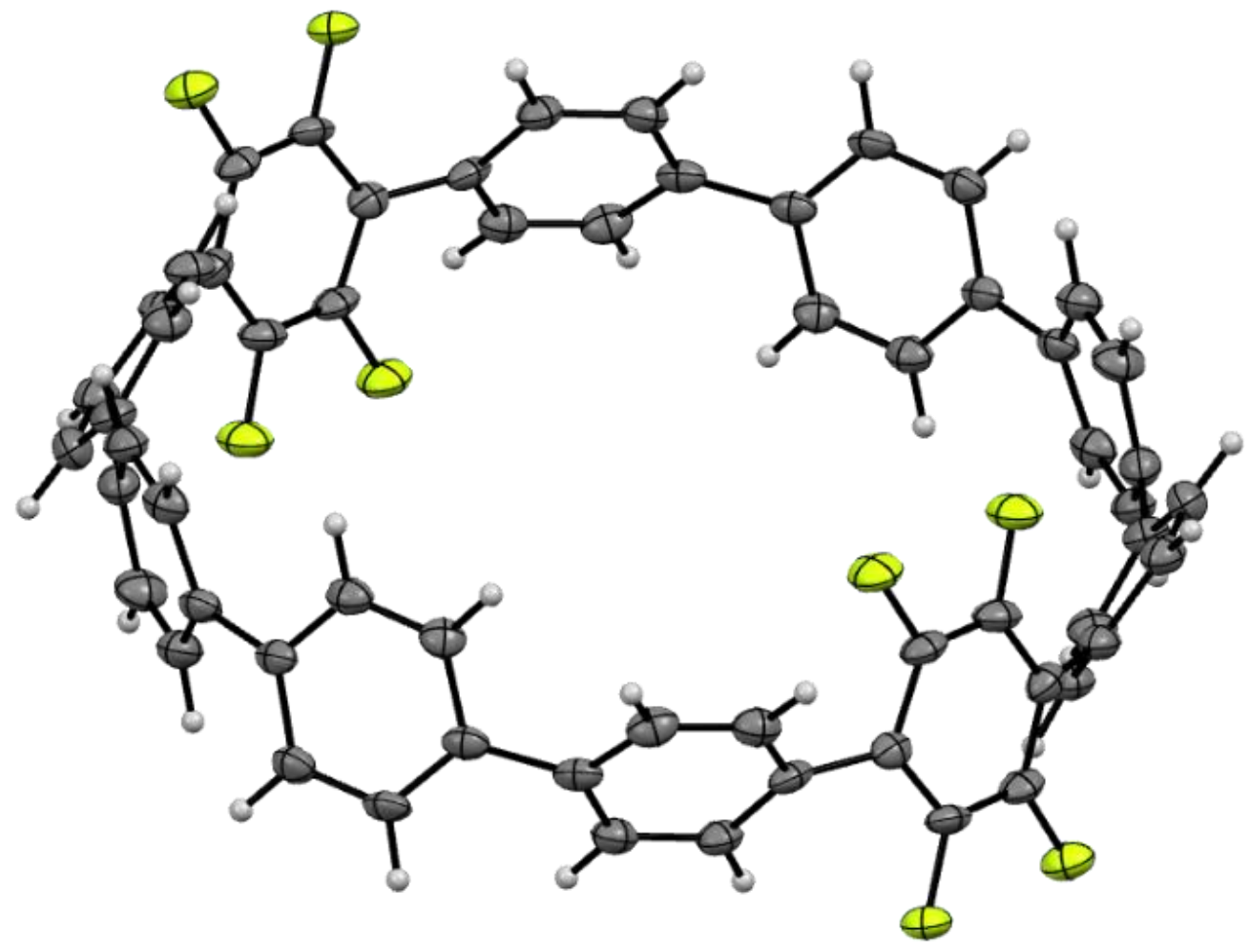

Figure S8. Molecular structure of nanohoop 2, with ellipsoids drawn at the 50\% probability level. Crystals were grown via layering of pentane onto a solution of $\mathbf{2}$ in THF 


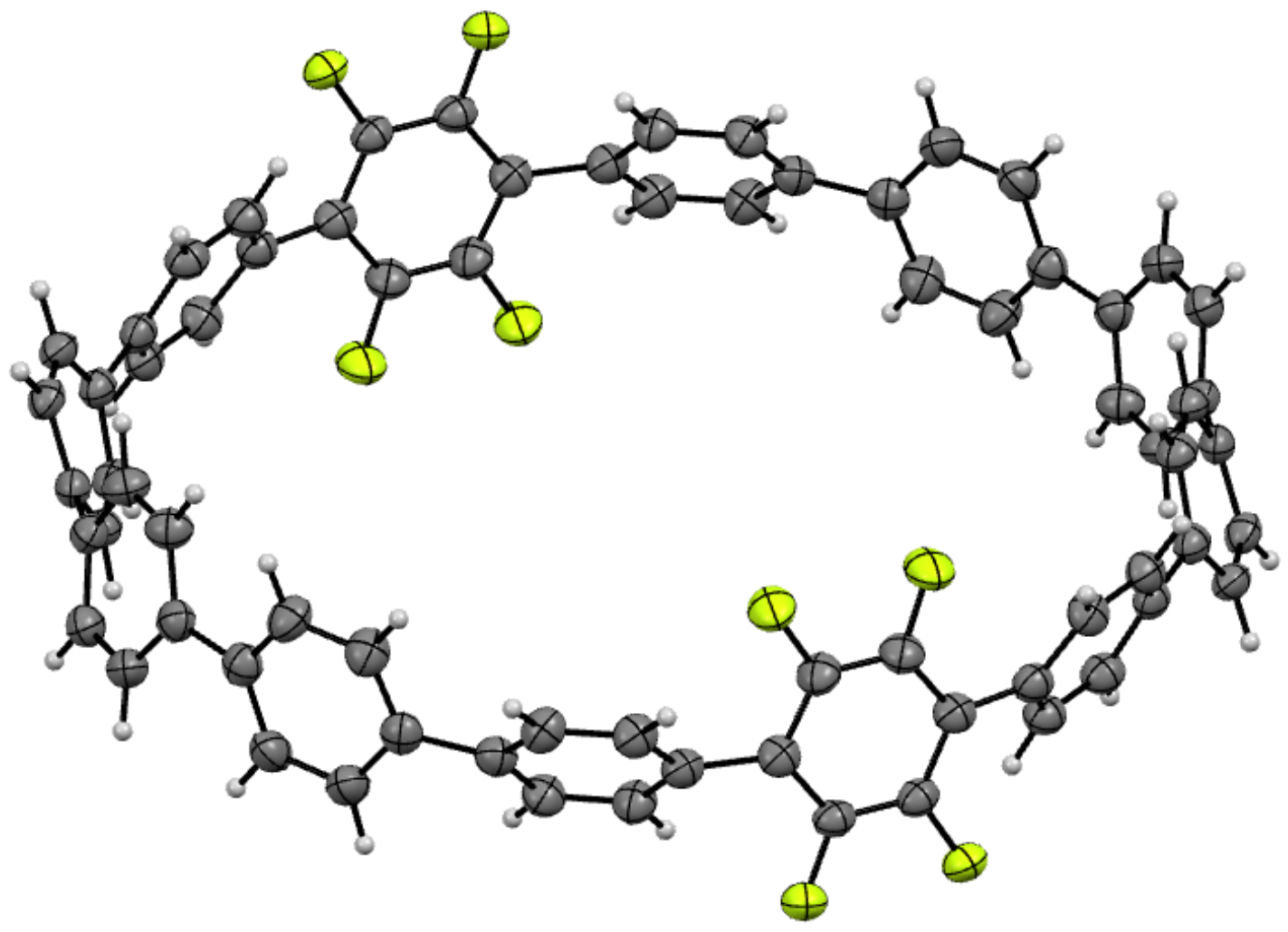

Figure 59. Molecular structure of nanohoop 3, with thermal ellipsoids drawn at the 50\% probability level. Crystals were grown via slow evaporation from $\mathrm{CH}_{2} \mathrm{Cl}_{2}$. 


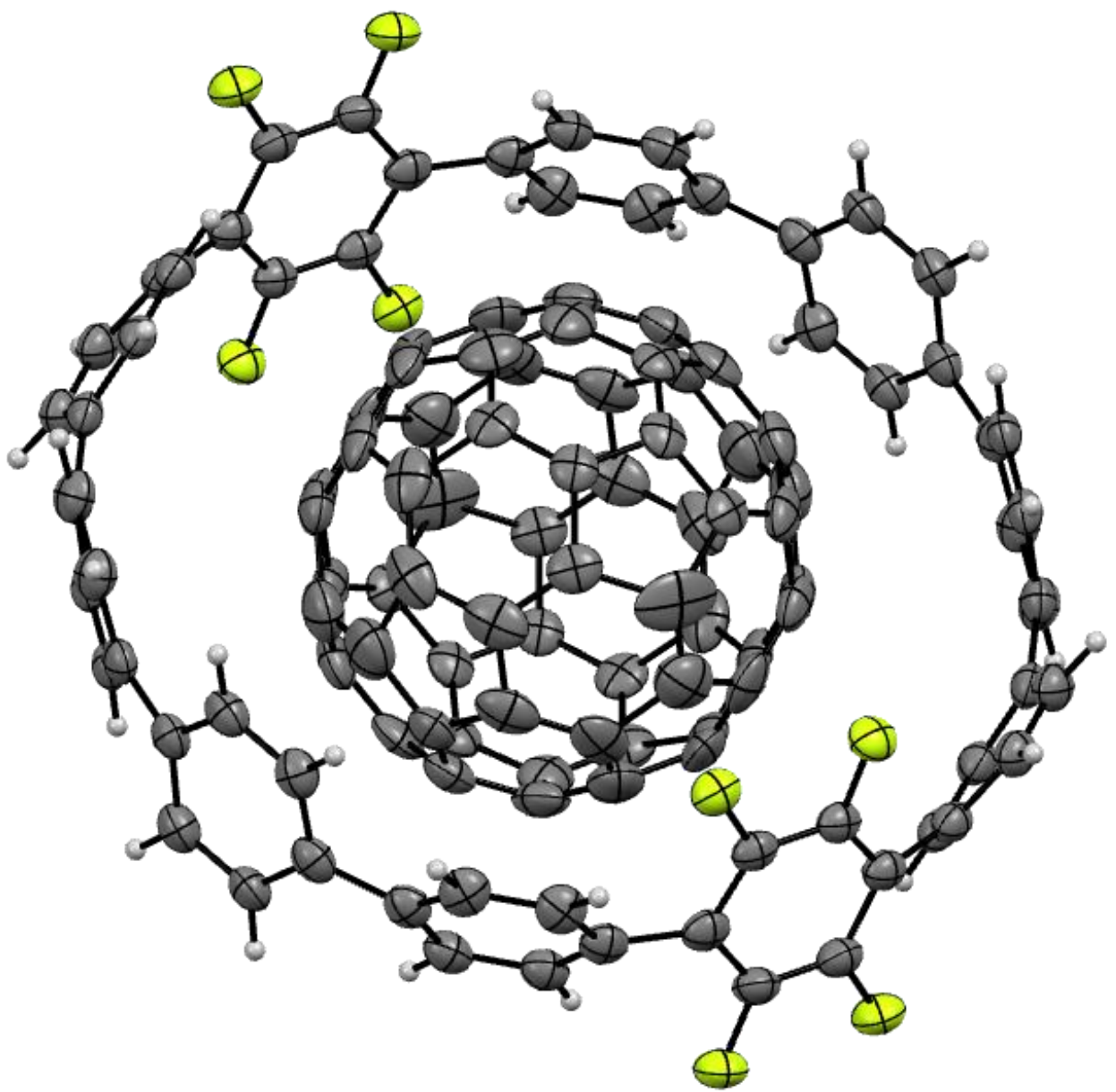

Figure S10. Molecular structure of $\mathrm{C}_{60} @ 2$, with thermal ellipsoids drawn at the $50 \%$ probability level. Crystals were grown grown via vapor diffusion of diethyl ether into a dilute THF/1,2-dichlorobenzene/toluene (1:1:1) solution of fluorinated nanohoop 2 and $\mathrm{C}_{60}(1: 1)$. 


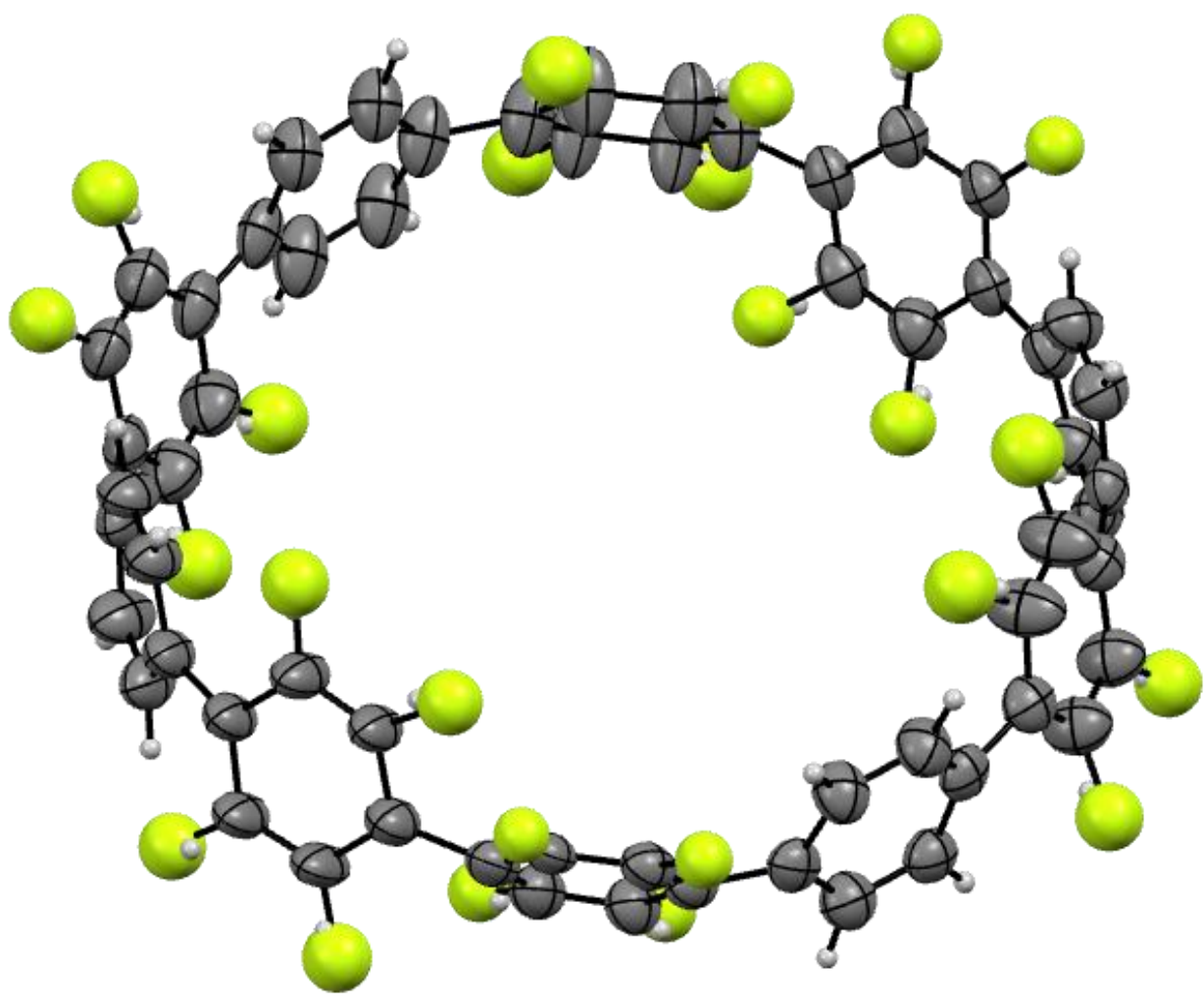

Figure S11. Molecular structure of $\mathbf{2 S}$, with thermal ellipsoids drawn at the $50 \%$ probability level. Fluorine atoms were found to be disordered throughout the structure. Crystals were grown via layering pentane onto a solution of $2 \mathrm{~S}$ in THF. 


\section{Thermogravimetric (TGA) Analysis of Nanohoop 1}

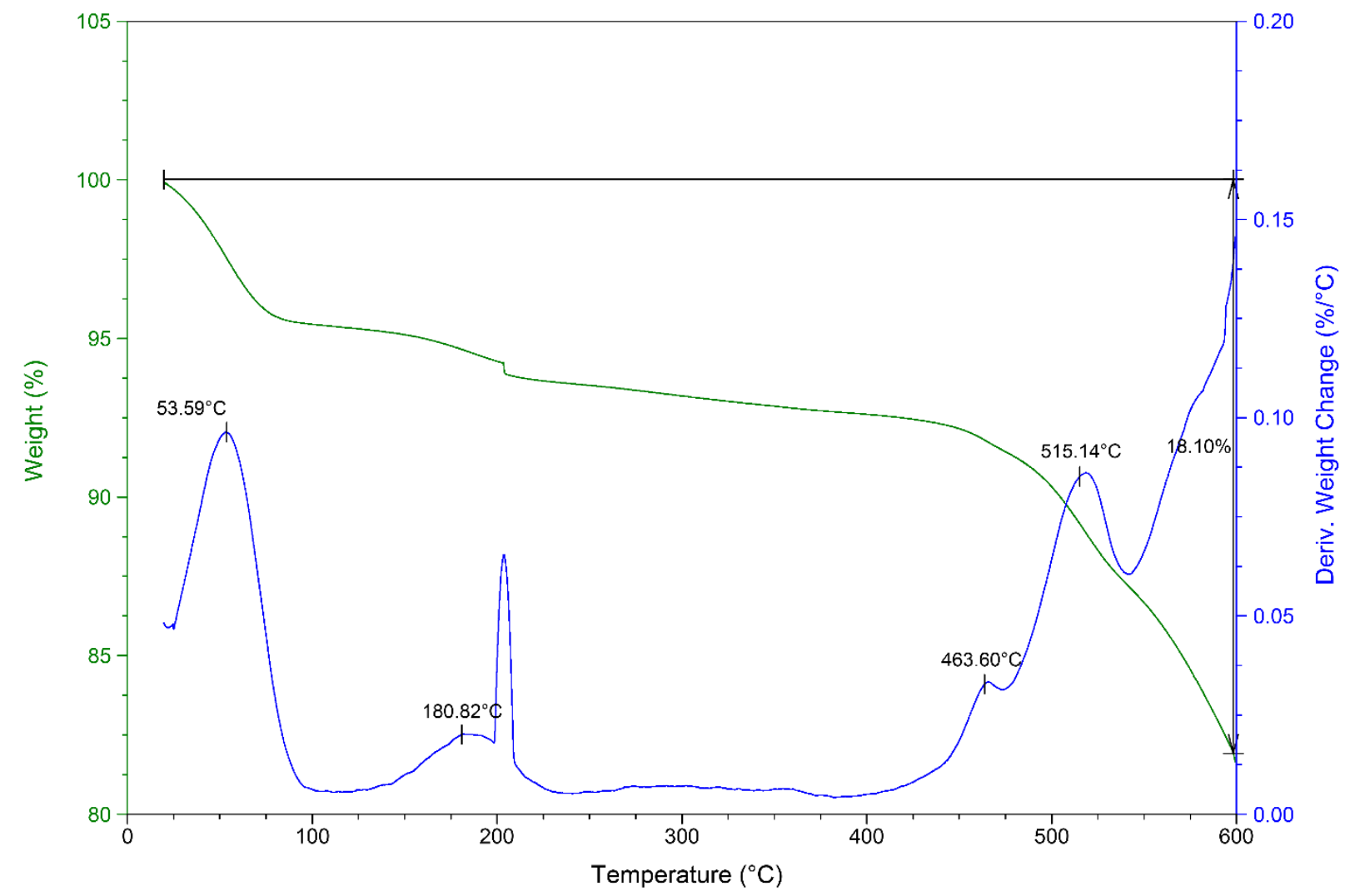

Figure S12. TGA analysis of nanohoop 1. The sharp mass loss at $\sim 210^{\circ} \mathrm{C}$ is attributed to a physical loss of material from the sample pan. 


\section{$\mathbf{N}_{\mathbf{2}}$ Uptake Studies}

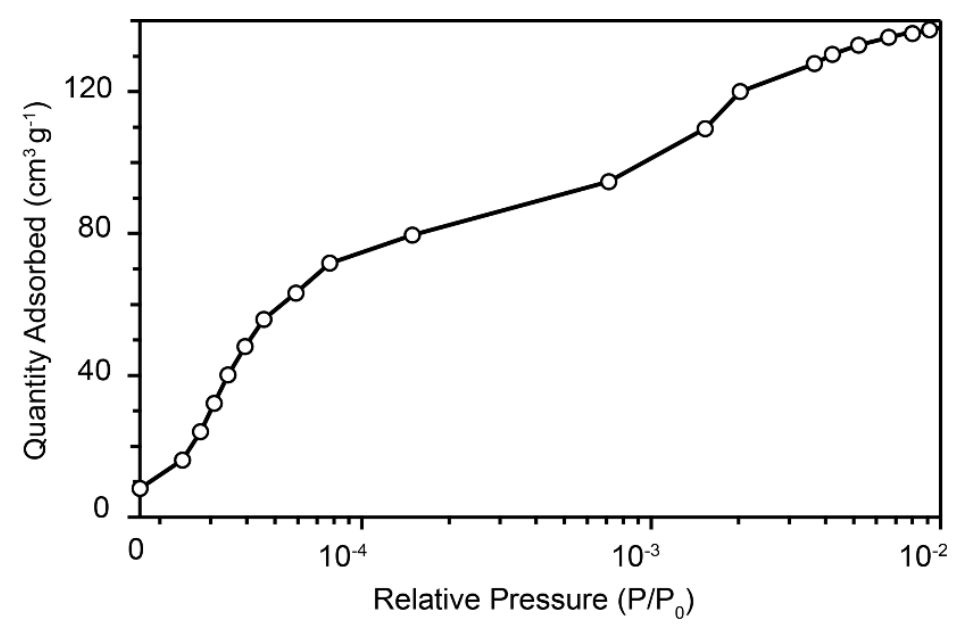

Figure S13. $\mathrm{N}_{2}$ uptake isotherm of nanohoop 1 shown at low relative pressures $\left(\mathrm{P} / \mathrm{P}_{0}\right)$ in semi-log scale.

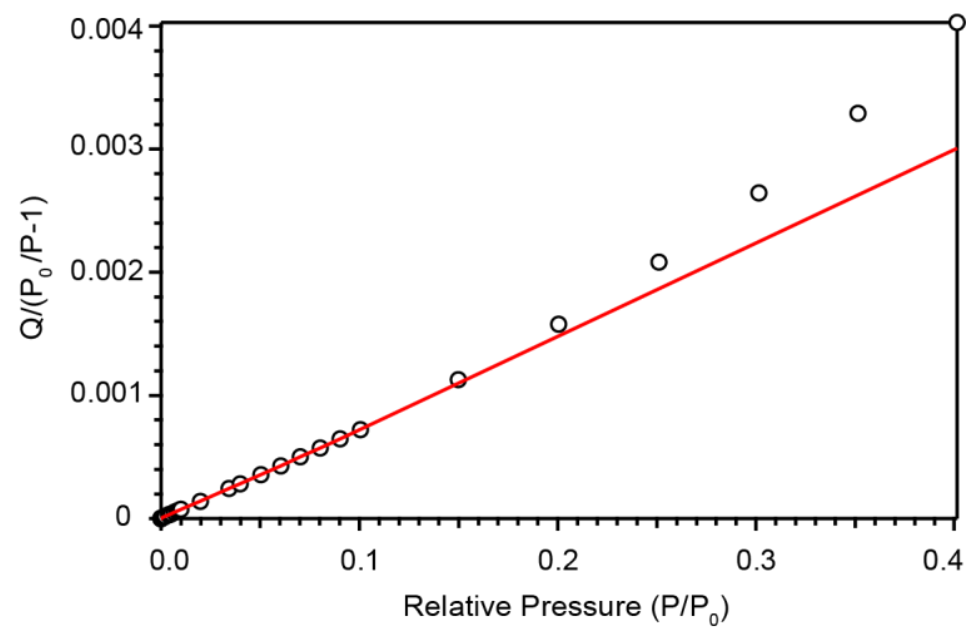

Figure S14. Brunauer-Emmett-Teller (BET) plot of nanohoop 1. Analysis was based on a linear fit (shown in red) to $\mathrm{N}_{2}$ isotherm data at relative pressures between $10^{-5}-10^{-1} \mathrm{P} / \mathrm{P}_{0}$. 


\section{Powder X-Ray Diffraction Data for Nanohoop 1}

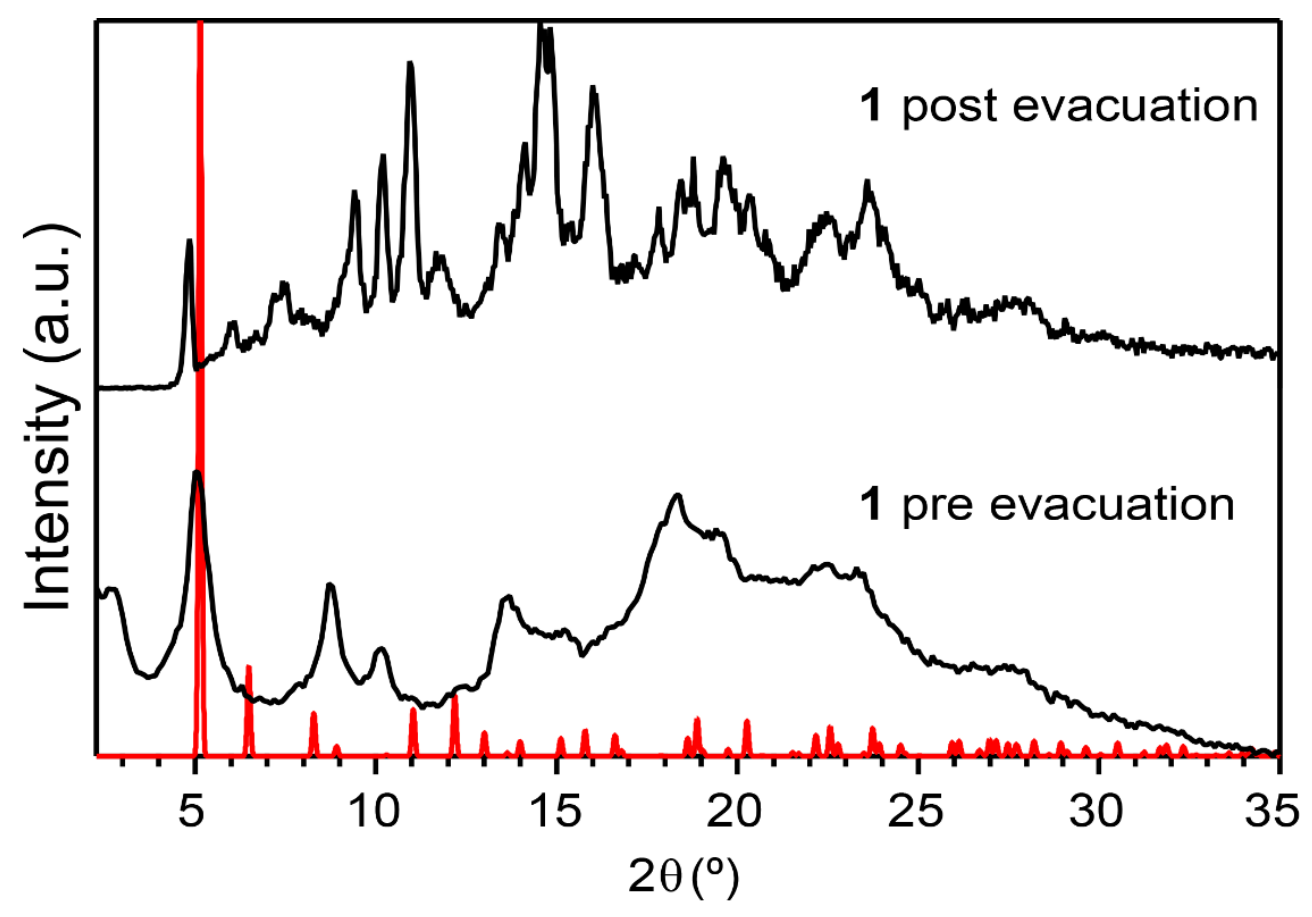

Figure S15. Powder X-ray diffraction (PXRD) data for nanohoop 1 before (bottom) and after (top) evacuation to 2 $\mu$ torr at $125^{\circ} \mathrm{C}$. Calculated PXRD pattern for $\mathbf{1}$ based on the provided crystal structure is shown in red (calculated using Mercury visualization software ${ }^{1}$ ). 


\section{Offset-Tubular Dimer of [10]CPP}

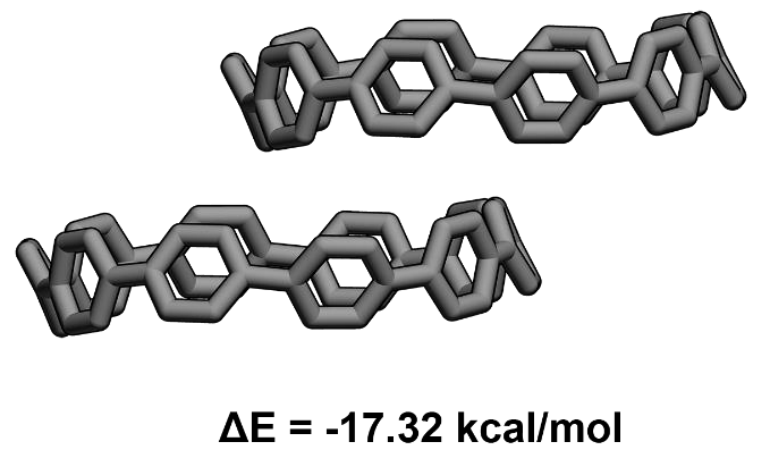

Figure S16. Offset-tubular dimer extracted from the herringbone-like crystal structure of [10]CPP. ${ }^{2}$ 


\section{Computational Analysis of Nanohoop 1}

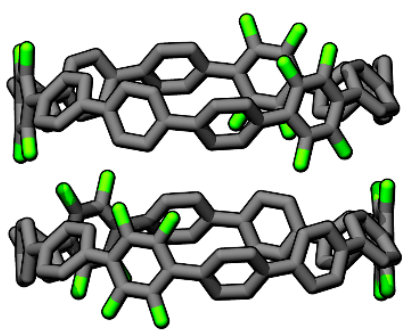

$\Delta E=-25.23 \mathrm{kcal} / \mathrm{mol}$

Figure S17. Tubular-like dimer extracted from the crystalline structure of nanohoop 1.

a)
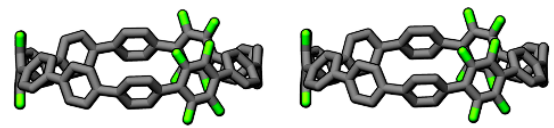

$\Delta \mathrm{E}=-11.71 \mathrm{kcal} / \mathrm{mol}$

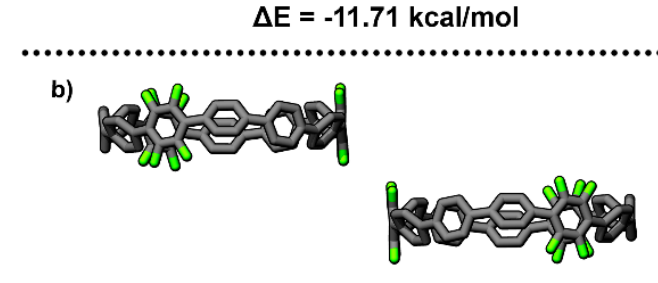

$\Delta \mathrm{E}=-0.91 \mathrm{kcal} / \mathrm{mol}$

c)
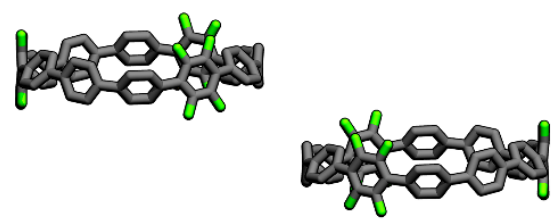

$\Delta \mathrm{E}=-0.79 \mathrm{kcal} / \mathrm{mol}$

Figure S18. Set of lateral-like dimers extracted from the crystalline structure of nanohoop 1. 


\section{References:}

1. Macrae, C. F.; Bruno, I. J.; Chisholm, J. A.; Edgington, P. R.; McCabe, P.; Pidcock, E.; RodriguezMonge, L.; Taylor, R.; van de Streek, J.; Wood, P. A. Mercury CSD 2.0 - New Features for the Visualization and Investigation of Crystal Structures. J. Appl. Cryst. 2008, 41, 466-470.

2. Reche-Tamayo, M.; Moral, M.; Pérez-Jiménez, A. J.; Sancho-García, J. C. Theoretical Determination of Interaction and Cohesive Energies of Weakly Bound Cycloparaphenylene Molecules J. Phys. Chem. C 2016, 120, 22627-22634. 